\title{
The interaction of $\beta 2$-microglobulin and gold nanoparticles: impact of coating, charge and size
}

\author{
Cristina Cantarutti, ${ }^{[a]}$ Paolo Bertoncin, ${ }^{[b]}$ Sofia Giorgetti, ${ }^{[c]}$ Vittorio Bellotti, ${ }^{[c, d]}$ Federico Fogolari ${ }^{[e, f]}$ and Gennaro \\ Esposito* [e,f,g]
}

[a] DAME Università di Udine, p.le M. Kolbe 4, 33100 Udine Italy; [b] Dipartimento di Scienze della Vita, Università di Trieste, Via Weiss 2, 34128 Trieste, Italy; [c] Dipartimento di Medicina olecolare, Università di Pavia, Via Taramelli 3, 27100 Pavia, Italy; [d] Division of Medicine, University College of London, London NW3 2PF, UK; [e] INBB, Viale Medaglie d'Oro 305, 00136 Roma, Italy; ; [f] DMIF, Università di Udine, Viale delle Scienze, 33100 Udine, Italy; [g] Science and Math Division, New York University Abu Dhabi, PO Box 129188, Abu Dhabi, UAE

E-mail: rino.esposito@uniud.it

\begin{abstract}
Gold nanoparticles (AuNPs) proved to be ideal scaffolds to build nanodevices whose performance can be tuned by changing their coating. In particular, their interaction with proteins revealed to be highly dependent on the physico-chemical properties of the gold cluster protecting monolayer. In this work we studied the behavior of three different alkanethiolate-coated AuNPs (AT-AuNPs) when they are incubated with a model amyloidogenic protein, $\beta 2$-microglobulin $(\beta 2 \mathrm{~m})$, responsible for dialysis-related amyloidosis (DRA). We synthesized 6-mercaptohexanoic acid-coated AuNPs (MHA-AuNPs) and (11-mercaptoundecyl)$\mathrm{N}, \mathrm{N}, \mathrm{N}$-trimethylammonium bromide-coated AuNPs (MUTAB-AuNPs) of $7.5 \mathrm{~nm}$ diameter and 3mercaptopropionic acid-coated AuNPs (MPA-AuNPs) of $3.6 \mathrm{~nm}$ diameter. To study the effects of the incubation with $\beta 2 \mathrm{~m}$ of these NPs that differ in charge and dimension, we employed NMR, UV-Vis and fluorescence spectroscopy, along with transmission electron microscopy (TEM). The tested AuNP systems gave different results. MHA-AuNPs precipitate with the protein into large agglomerates inducing $\beta 2 \mathrm{~m}$ unfolding. MUTAB-AuNPs precipitation is triggered by the protein that remains unchanged in solution, at least at the higher considered protein/NP ratio. MPA-AuNPs interact preferentially with a localized region of the protein that stays essentially dissolved. These results stress the complexity of the bio-nano interface and the viability of a fine control of NP properties to master protein-NP interactions.
\end{abstract}

\section{Introduction}

The peculiar characteristics of gold nanoparticles (AuNPs), such as high surface-to-volume ratio, ease of production and functionalization, distinctive optical properties and low toxicity, has made them really intriguing tools to be employed in many different areas.[1-3] However, the opportunities and potentialities of widespread applications are hindered by concerns about their biological and environmental safety.[4,5] From a toxicological point of view, particular attention has been devoted to AuNPs molecular interaction with functional biomolecules, especially proteins. It has been demonstrated, indeed, that in a biological milieu AuNPs immediately adsorb proteins on their surface with unpredictable consequences on AuNP stability and on protein structure and functionality. $[6,7]$ The elucidation of the protein-NP interacting pathways has proved to be particularly challenging because AuNP behavior is highly dependent on their physicochemical properties. Along with a gold core whose dimensions can be controlled, AuNPs are covered by an organic layer which is in direct contact with the external environment and determines their surface characteristics. Among the possible ligands, thiols are the ones that produce the more stable organic monolayer grafted on gold nanoparticles.[8] The advantage of using thiols is that they can bear different $\omega$-functional groups that decorate the gold cluster surface. Between the thiol headgroup and the tail there is a linker chain, usually alkylic or ethylenglycolic, that adds stability to the supramolecular system. Nanoconjugates made by gold nanoparticles and alkanethiols terminated with amines, oligonucleotides, peptides and antibodies have been synthesized and applied in gene transfection,[9-12] drug delivery,[13-15] imaging[16] and photothermal therapy.[17] These promising results should, nevertheless, be evaluated by considering also biocompatibility and biodistribution issues. It has been demonstrated that the toxicity of nanoconjugates is highly dependent on 
the size,[18] the shape[19] and the chemical properties of the surface ligands.[20] Here we present the investigation of the effects of the interaction between three different types of AuNPs and an amyloidogenic model protein, namely $\beta 2$ microglobulin $(\beta 2 \mathrm{~m})$, on both NP stability and protein conformation. It is known that AuNP colloidal stability can be either improved or destroyed by the presence of proteins[21,22] and that AuNPs can either affect protein conformation or leave it unchanged. $[23,24]$ Concerning amyloidogenic proteins, it has been demonstrated that AuNPs can either promote or inhibit fibril formation.[25] In relation to the chosen protein model, in particular, citrate-stabilized AuNPs were shown to prevent fibrillogenesis of a highly amyloidogenic variant of $\beta 2 \mathrm{~m}, \mathrm{D} 76 \mathrm{~N} \beta 2 \mathrm{~m}$.[26] In this work, we report the response of AuNP- $\beta 2 \mathrm{~m}$ system on changing the AuNP surface charge and the size. To this aim, different alkanethiols were employed to synthesize alkanethiolate-covered AuNPs (AT-AuNPs). After the incubation with $\beta 2 \mathrm{~m}$, the AT-AuNP stability was assessed by UV-Vis spectroscopy and transmission electron microscopy. The protein conformation was probed by two-dimensional NMR and fluorescence spectroscopy. We obtained different results with the three considered AT-AuNP systems, but an overall outcome stressing the relevance of the AuNP coating properties in determining the mechanisms of interaction with proteins.

\section{Results and Discussion}

\section{AT-AuNP synthesis and characterization}

We synthesized 6-mercaptohexanoic acid-coated AuNPs (MHA-AuNPs), (11-mercaptoundecyl)-N,N,Ntrimethylammonium bromide-coated AuNPs (MUTAB-AuNPs) and 3-mercaptopropionic acidcoated AuNPs (MPA-AuNPs). The synthesis of these AT-AuNPs was performed by following procedures already reported in literature with minor changes (Scheme 1).[27-29] MHA-AuNPs and MUTAB-AuNPs were obtained through ligand-exchange reactions, directly and indirectly, respectively, from citratestabilized AuNPs with $7.5 \pm 1.0 \mathrm{~nm}$ average diameter. The shift of the surface plasmon band (SPB) in the UV-Vis spectrum after the exchange assessed the change in AuNP coating[27,28] (Figure 1a and 1c) and the core size distribution calculated from transmission electron microscopy (TEM) micrographs ruled out any onset of AuNP aggregation (Figure $1 \mathrm{~b}$ and $1 \mathrm{~d}$ ). By reducing directly $\mathrm{HAuCl} 4$ with $\mathrm{NaBH} 4$ in presence of MPA using an $\mathrm{Au} / \mathrm{MPA}$ ratio of $1 / 9$, a brown stable solution was obtained. From TEM images a particle average diameter of $3.6 \pm 1.2 \mathrm{~nm}$ was calculated (Figure 1e). The small dimensions of these AuNPs are consistent with the weak SPB recorded in the UV-Vis spectrum (Figure 1f). MPA-AuNPs can be centrifuged, dried and dispersed again without any aggregation. To evaluate the NP organic percentage content and confirm MPA composition, thermogravimetric analysis (TGA) analysis was performed (Figure 1g). From TGA results and NP diameter obtained from TEM, it was possible to estimate the molar concentration of $1 \mathrm{mg}$ of MPAAuNPs in $1 \mathrm{~mL}$, i.e. $2.8 \mu \mathrm{M}$ (see Experimental Section).

\section{AT-AuNP stability in presence of $\boldsymbol{\beta} \mathbf{2 m}$}

AT-AuNP solutions were found to be stable over time, but $\beta 2 \mathrm{~m}$ addition decreased their colloidal stability leading to precipitation. When MHA-AuNPs were mixed with $\beta 2 \mathrm{~m}$ (protein/NP $=600$ ), during the first days, no apparent agglomeration was observed. By adding increasing amounts of protein to the NP solution, a progressive SPR red shift was recorded (Figure 2a). The fitting of the SPR shift with the Langmuir adsorption[30] isotherm (Figure $2 \mathrm{~b}$ ) gave an association constant (Ka) value of $(0.18 \pm 0.018) x$ 106. It is worth noting that the application of the Langmuir model is a simplified approach to describe the absorption of molecules to a surface, but is not completely suited to protein-NP systems mainly because it assumes that there is only one type of binding site on the surface. It has been reported, in fact, that alkanethiolate monolayers self-assemble forming transient cavities with different binding affinities.[31] However the details of this process are not known for the specific system and therefore the qualitative assumption of a Langmuir model becomes operatively acceptable. After one month, a black precipitate was found on the bottom of the flask containing the protein-NP solution. The nearly complete precipitation of MHA-AuNPs was confirmed by UV-Vis spectroscopy (Figure 3a). 
a)

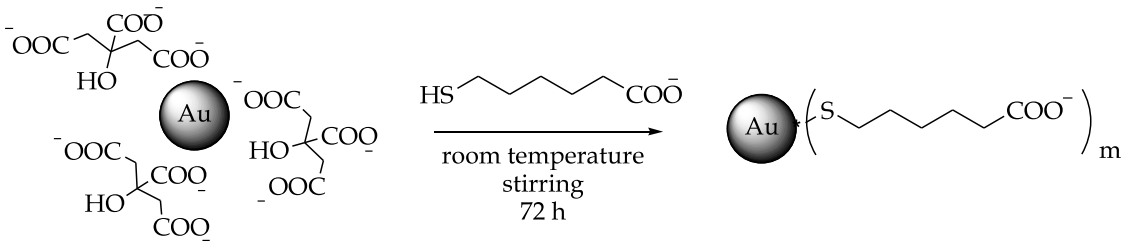

b)

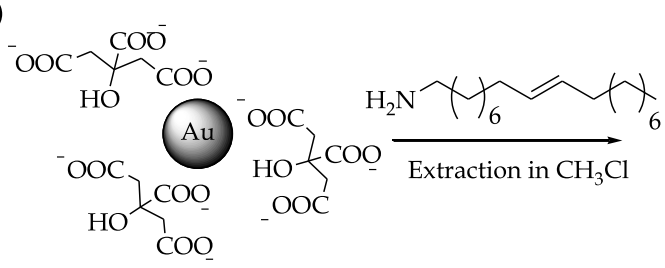

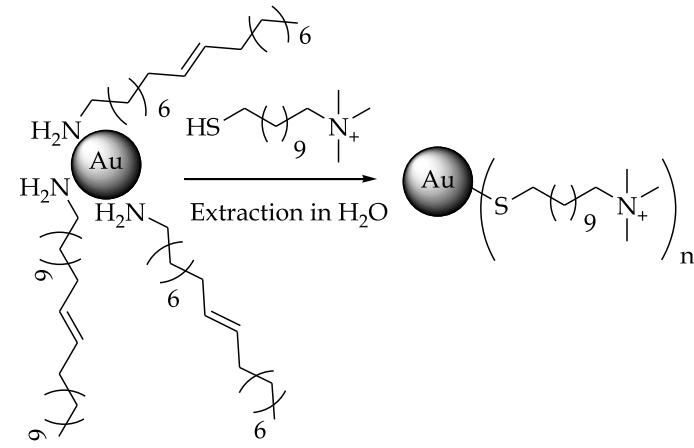

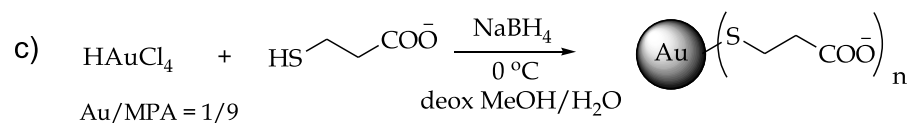

Scheme 1. AT-AuNPs synthesis. a) MHA-AuNPs, b) MUTAB-AuNPs (bromide ions are omitted in the drawing) and c) MPAAuNPs synthesis.

a)

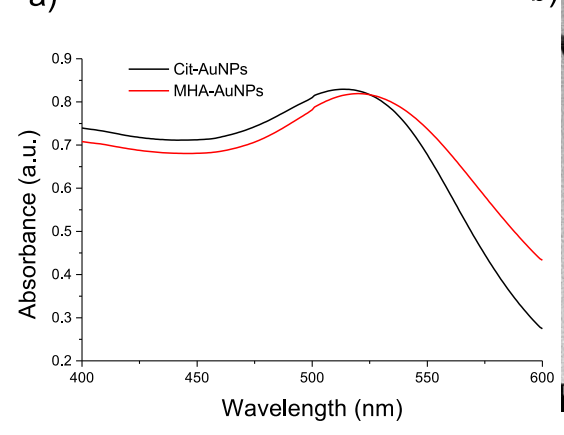

c)

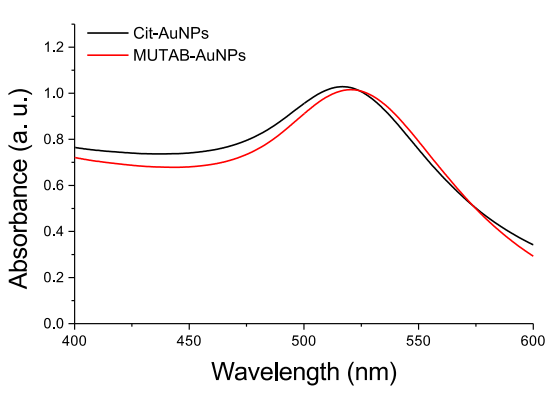

b)

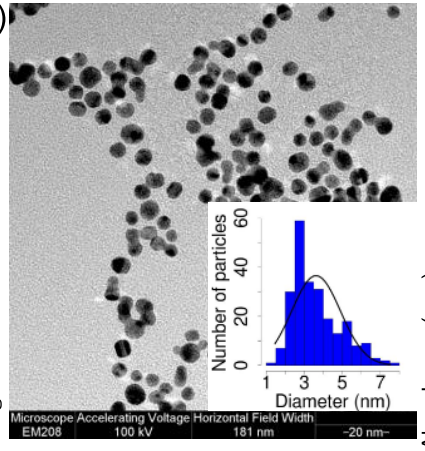

d)

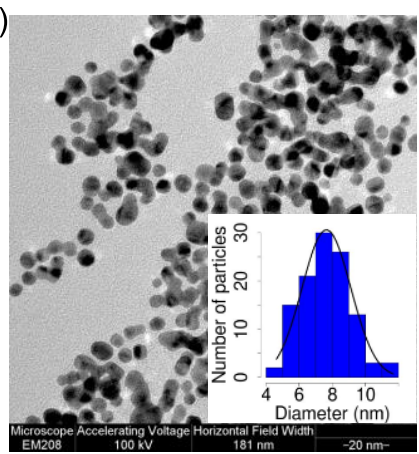

e)

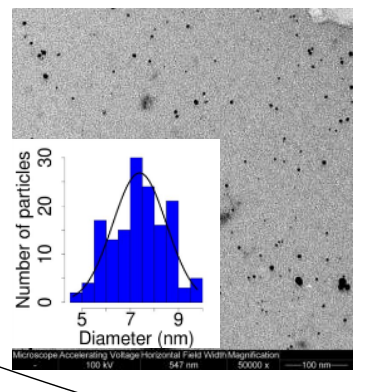

0.5
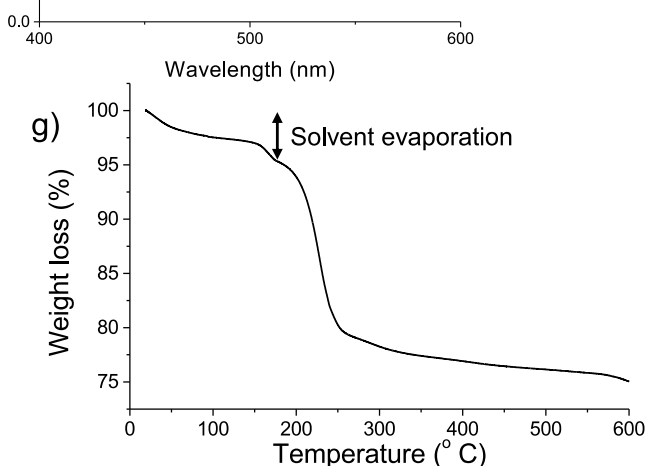

Figure 1. Characterization of synthesized AT-AuNPs: a) UV-Vis spectrum of Cit-AuNPs (black line) and MHA-AuNPs (red line); b) TEM micrograph of MHA-AuNPs along with the corresponding size histogram (the average dimeter was $7.4 \pm 1.1$ $\mathrm{nm}$ ); c) UV-Vis spectrum of Cit-AuNPs (black line) and MUTAB-AuNPs (red line); d) TEM micrograph of MUTAB-AuNPs along with the corresponding size histogram (the average dimeter was $7.4 \pm 1.2 \mathrm{~nm}$ ); e) TEM micrograph of MPA-AuNPs along with the corresponding size histogram (the average diameter was $3.6 \pm 1.2 \mathrm{~nm}$ ); f) UV-Vis spectrum of MPA-AuNPs and g) TGA analysis of MPA-AuNPs. 

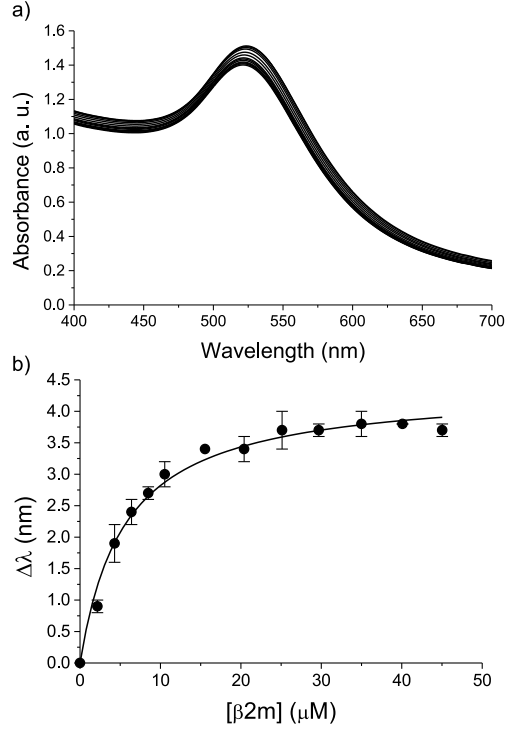

Figure 2. a) MHA-AuNP ( $25 \mathrm{nM}$ ) absorption spectra after the progressive addition of $\beta 2 \mathrm{~m}(0-45 \mu \mathrm{M})$ and $b)$ the corresponding SPR red shift as a function of the protein concentration fitted with Langmuir equation30 (black line). The experiment was done in triplicate and the error is reported as the standard deviation.

This precipitation phenomenon was attenuated in a sample in which the protein concentration was kept the same, but the NP concentration was two-fold. In this latter solution, AuNPs did not precipitate completely even after one month, but slowly settled as confirmed by UV-Vis spectra (Figure $3 b$ ).
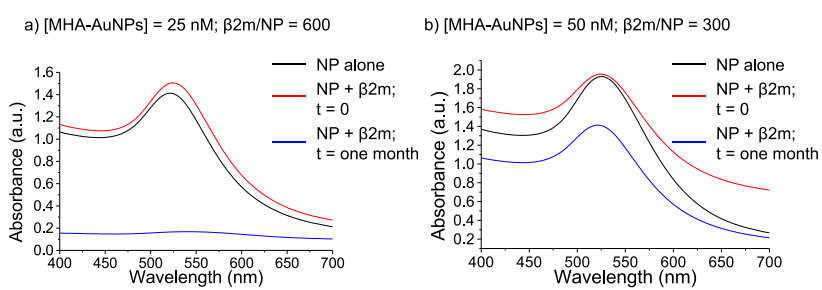

Figure 3. a) Absorption spectra of $25 \mathrm{nM}$ MHA-AuNPs alone (black) and in the presence of $15 \mu \mathrm{M} \beta 2 \mathrm{~m}$ soon after the solution preparation (red) and after one month (blue). b) Absorption spectra of $50 \mathrm{nM} \mathrm{MHA-AuNPs}$ alone (black) and in the presence of $15 \mu \mathrm{M} \beta 2 \mathrm{~m}$ soon after the solution preparation (red) and after one month (blue).

The MHA-AuNP precipitate formed after one month in presence of $\beta 2 \mathrm{~m}$ was briefly sonicated, deposited on a TEM grid and stained for imaging. TEM micrographs showed an agglomerated state of nanoparticles clearly embedded in a protein matrix represented by a grey halo (Figure $4 a$ and $4 b$ ). With the lower protein/NP ratio sample, this protein matrix was less evident, but big NP aggregates could still be observed (Figure 4c). The same colloiddestabilising effect of the protein was even more

accentuated with MUTAB-AuNPs. Soon after the preparation of protein-NP solutions, the MUTABAuNP less concentrated solution started to aggregate and the more concentrated solution started to settle as can be seen in the UV-Vis spectra (Figure 5).

a)

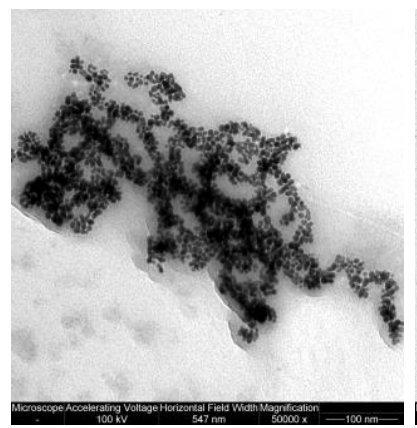

b)

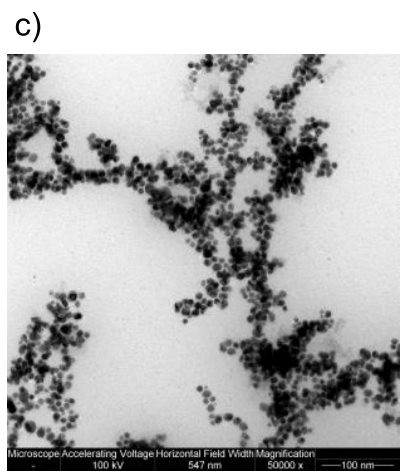

Figure 4. a) and b) TEM micrographs of sonicated precipitate made by $25 \mathrm{nM}$ MHA-AuNPs and $15 \mu \mathrm{M} \beta 2 \mathrm{~m}$. c) TEM micrograph of $50 \mathrm{nM}$ MHA-AuNPs in the presence of $15 \mu \mathrm{M} \beta 2 \mathrm{~m}$.
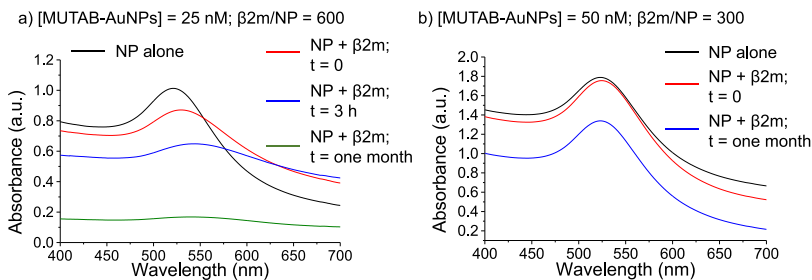

Figure 5. a) Absorption spectra of $25 \mathrm{nM}$ MUTAB-AuNPs alone (black) and in the presence of $15 \mu \mathrm{M} \beta 2 \mathrm{~m}$ soon after the solution preparation (red), after three hours (blue) and after one month (green). b) Absorption spectra of $50 \mathrm{nM}$ MHA-AuNPs alone (black) and in the presence of $15 \mu \mathrm{M}$ $\beta 2 \mathrm{~m}$ soon after the solution preparation (red) and after one month (blue).

The sudden nanoparticle agglomeration could be easily followed with UV-Vis by titrating MUTABAuNPs with the protein. The subsequent addition of $\beta 2 \mathrm{~m}$ led to progressive broadening reflecting the aggregation that occurred in solution (Figure 6). TEM 
images of the sonicated precipitate obtained from 25 nM MUTAB-AuNPs and $15 \mu \mathrm{M} \beta 2 \mathrm{~m}$ mixture showed nanoparticle agglomerates, but no distinctive evidence of protein presence inside those agglomerates could be detected even after staining the sample with uranyl acetate (Figure 7a). On decreasing the protein/NP ratio to 300 , the scenario became very similar to the one found with MHAAuNPs, i.e. the grey halo that is usually attributed to the protein could be detected around the nanoparticle clusters (Figure $7 \mathrm{~b}$ ). When $\beta 2 \mathrm{~m}$ was added to MPA-AuNP solution, after a few hours a brownish precipitate was observed. It could be easily dispersed again and when imaged, nanoparticles proved to be well dispersed (Figure 8) with almost the same size distribution as the NPs alone. The effects of the interaction on MPA-AuNPs could not be followed with UV-Vis spectroscopy because the SPR band of these small NPs was too broad (Figure 1f).

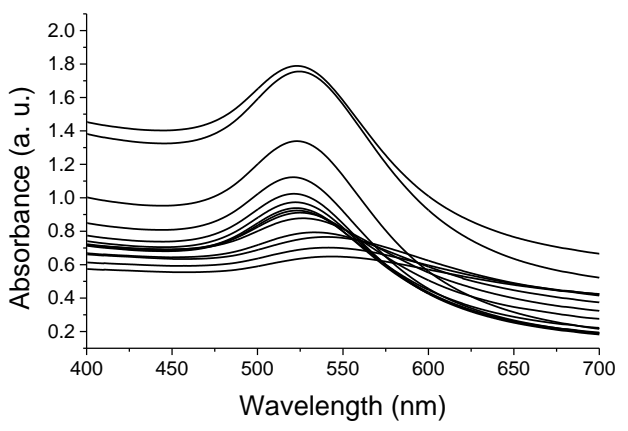

Figure 6. MUTAB-AuNP ( $25 \mathrm{nM}$ ) UV-Vis spectra after the progressive addition of $\beta 2 \mathrm{~m}$ from 0 to $45 \mu \mathrm{M}$. a)

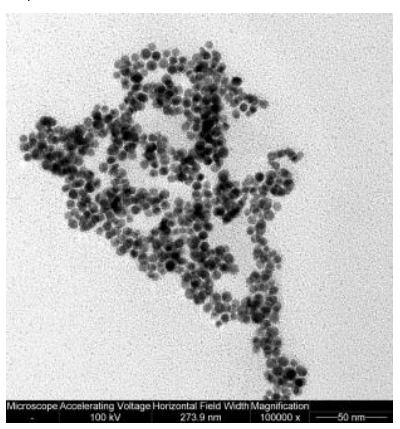

b)

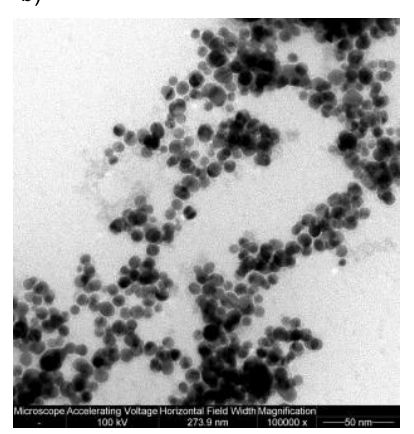

Figure 7. a) TEM micrograph of sonicated precipitate made by $25 \mathrm{nM}$ MUTAB-AuNPs and $15 \mu \mathrm{M} \beta 2 \mathrm{~m}$ stained with uranyl acetate and b) TEM micrograph of $50 \mathrm{nM} \mathrm{MHA-}$ AuNPs in the presence of $15 \mu \mathrm{M} \beta 2 \mathrm{~m}$.

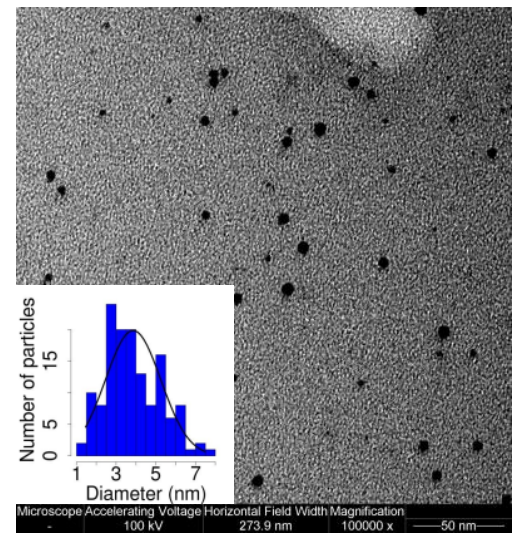

Figure 8. TEM micrograph of sonicated $2.5 \mu \mathrm{M}$ MPAAuNPs and $15 \mu \mathrm{M} \beta 2 \mathrm{~m}$, along with the corresponding size histogram (the average dimeter was $3.8 \pm 1.3 \mathrm{~nm}$ ).

\section{$\beta 2 \mathrm{~m}$ characterization in presence of AT-AuNPs}

Two-dimensional NMR was employed to analyse the conformational state of the protein upon its interaction with AT-AuNPs. The $15 \mathrm{~N}-1 \mathrm{H}$ SOFAST $\mathrm{HMQC}$ [32] spectra of $\beta 2 \mathrm{~m}$ recorded in presence of MHA-AuNPs (protein/NP $=600$ ) and compared to the control (Figure 9a and S1), showed an intensity decrease soon after the preparation, with average relative intensity (Rlav) of $0.81 \pm 0.13$, and the complete loss of the protein $15 \mathrm{~N}-1 \mathrm{H}$ correlations after one month (Figure 9b). The relative intensities of the individual residues are reported in Supplementary Information (Figure S2a). The intensity decrease dropped to $0.46 \pm 0.092$ at higher MHA-AuNP concentration (protein/NP = 300) (Figure S2c). Over the short term, the sample with higher MHA-AuNPs concentration showed $24 \%$ signal loss and the onset of new peaks in the random coil region suggesting a partial loss of tertiary structure due to local unfolding (red trace in Figure 9a). 

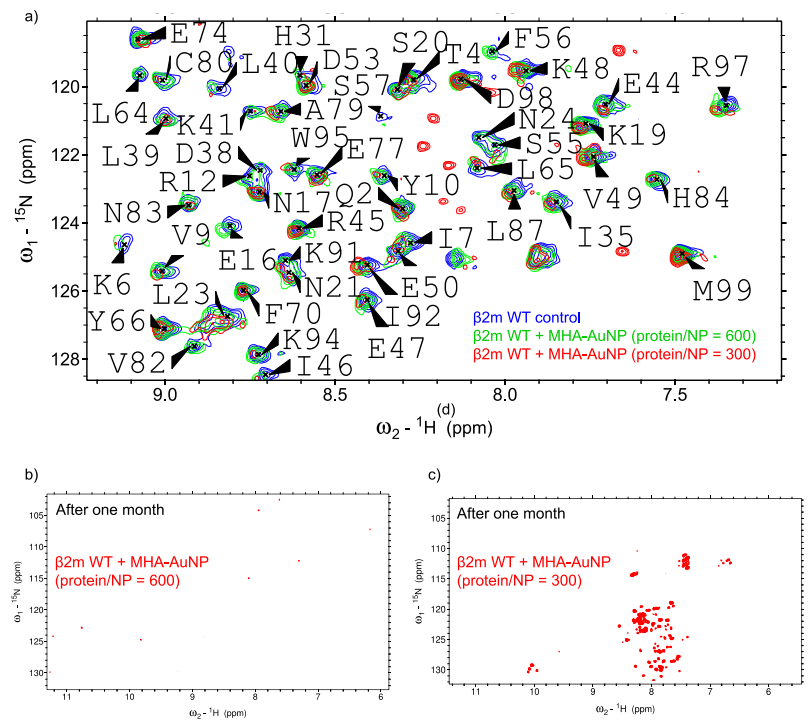

Figure 9. a) Region from the superimposition of $\beta 2 \mathrm{~m}$ WT $15 \mathrm{~N}-1 \mathrm{H}$ SOFAST HMQC spectra recorded at $500 \mathrm{MHz}(1 \mathrm{H}$ frequency) without (blue) and with MHA-AuNP (protein/NP = 600 in green and protein/NP = 300 in red). The whole map is reported in Figure S1. b) and c) $\beta 2 \mathrm{~m} 1 \mathrm{H}$ $15 \mathrm{~N}$ SOFAST HMQC spectra from the same samples with protein to NP ratio of 600 and 300 , respectively, recorded after one month. The corresponding backbone amide assignments are reported by single letter code.

This denaturation effect extended essentially to the whole molecule after one month (Figure 9c). At both protein/NP ratios, the intensity decrease was not uniformly distributed along the protein backbone, but there were some signals that proved more affected by the NP presence (Figure S2a and S2c). In addition to this attenuation pattern, the average variations of the combined chemical shifts[33] ( $\triangle \delta$ Sav $=0.015 \pm 0.0077 \mathrm{ppm}$ for protein $/ \mathrm{NP}=600$ and $\Delta \delta \mathrm{av}$ $=0.023 \pm 0.0096 \mathrm{ppm}$ for protein $/ \mathrm{NP}=300$ ) were significant, considering the experimental $\Delta \delta$ uncertainty $( \pm 9.8 \times 10-3 \mathrm{ppm})[33$ ] (Figure S2b and S2c). The most perturbed signals, i.e. relative intensity and chemical shift perturbation displaced more than one standard deviation from the average value, did not belong to residues clustering in restricted regions, but to locations rather spread over the protein structure, involving strands on both $\beta$-sheets and $A B$ loop apical region (Figure 10). For the complete list of the outlier residues see Supplementary Information (Table S1). When MUTAB-AuNPs were mixed with $\beta 2 \mathrm{~m}$ in a ratio of 1 to 600 , the two-dimensional spectrum (Figure 11 and S3) did not show an overall significant intensity variation (Rlav $=1.01 \pm 0.093$ ) and only small deviations of the combined chemical shifts $(\Delta \delta a v=$
$0.0047 \pm 0.029 \mathrm{ppm}$ ) could be detected (Figure S4a and S4b). In spite of the limited magnitude of the average intensity and chemical shift variations, a few residues could be detected to be particularly affected by the presence of MUTAB-AuNPs. In addition to the apical locations in loops $A B, B C, D E$ and $E F$, also the amides of some residues in $B, D$ and $E$-strands presented small perturbations (Figure 12a and Table S2), whose extent did not change significantly after one month (data not shown).

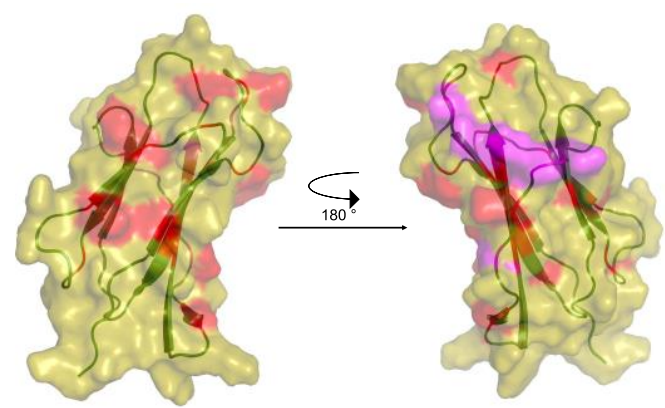

Figure 10. $\beta 2 \mathrm{~m}$ WT cartoon highlighting in red the locations of the residues that were more affected by MHAAuNPs presence with protein/NP $=600$ and in magenta the additional ones revealed with protein/NP $=300$.

When the protein/NP ratio was decreased by doubling the NP concentration, the average relative intensity dropped down to $0.32 \pm 0.068$ and the average perturbation of the combined chemical shifts raised to $0.014 \pm 0.010 \mathrm{ppm}$ (Figure S4c and S4d). The protein spectrum revealed a quite strong interaction affecting again the $\mathrm{C}$-terminal apical region with a quite extended involvement of the Cterminal tail and of the C-C'-D loop (Figure $12 \mathrm{~b}$ and Table S2) at the opposite edges of the two $\beta$-sheets of the structure. In contrast with the AuNP systems just described, MPA-AuNPs could be dried and dispersed without causing aggregation, thereby allowing very high NP concentrations. Five different protein/NP ratios were examined in the range 100 10. The corresponding HMQC spectra (Figure 13 and S5) showed a preferential intensity decrease of some peaks and, in addition, a progressive general attenuation with the protein/NP ratio lowering that, besides partial precipitation, was reflecting the increase of protein recruitment with the number of available interaction sites on NPs (Figure S6a). The gradual intensity attenuation was also associated with a progressive chemical shift variation (Figure S6b). 


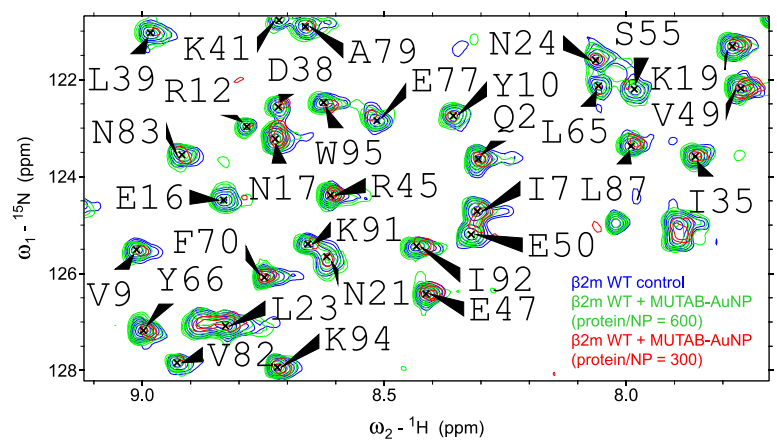

Figure 11. Region from the superimposition of $\beta 2 \mathrm{~m}$ WT $15 \mathrm{~N}-1 \mathrm{H}$ SOFAST HMQC spectra recorded at $500 \mathrm{MHz}(1 \mathrm{H}$ frequency) without (blue) and with MUTAB-AuNP (protein/NP = 600 in green and protein/NP = 300 in red). The corresponding backbone amide assignments are reported by single letter code. The whole map is reported in Figure S3.

a)
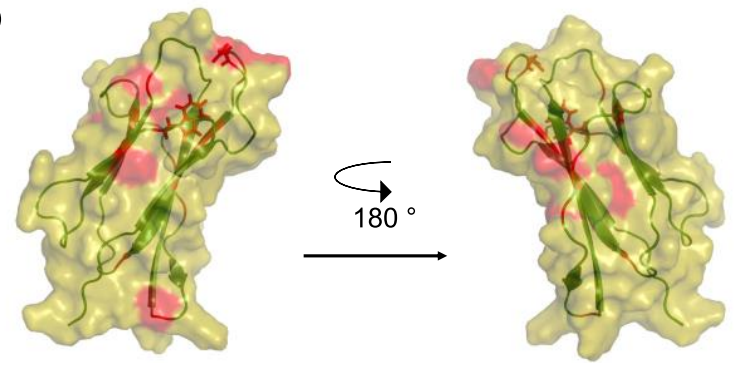

b)
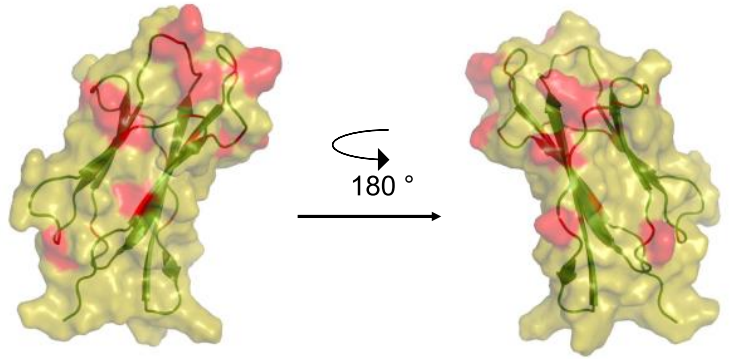

Figure 12. $\beta 2 \mathrm{~m}$ WT cartoon highlighting in red the locations of the residues that were most affected by MUTAB-AuNPs presence reported in a) for protein/NP = 600 and in b) for protein/MUTAB-NP $=300$.

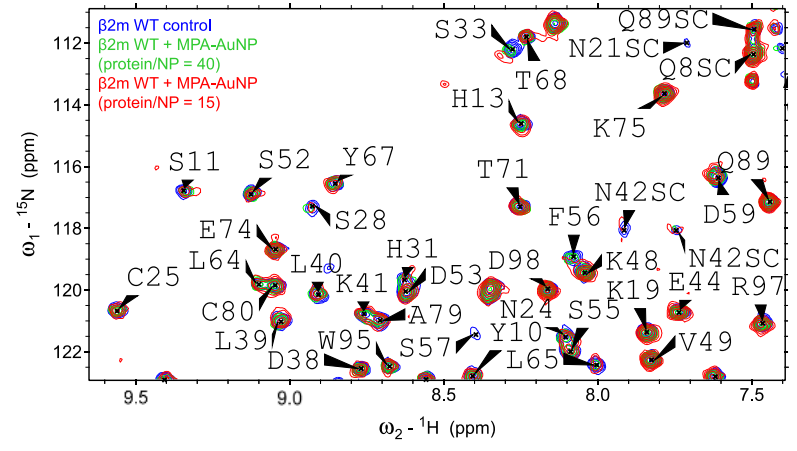

Figure 13. Region from the superimposition of $\beta 2 \mathrm{~m} 1 \mathrm{H}$ $15 \mathrm{~N}$ SOFAST HMQC spectra recorded at $500 \mathrm{MHz}(1 \mathrm{H}$ frequency) in absence of MPA-AuNPs (blue) and in presence of MPA-AuNPs with protein/NP ratio of 40 (green) and of 15 (red). The corresponding backbone amide assignments are reported by single letter code and the side-chain amides are indicated with SC. The whole map is reported in Figure S5.

With these small negatively charged NPs, a quite localized, preferential region was found to be involved in the interaction (Figure 14 and Table S3). The patch includes two loops, namely BC loop and DE loop, and the spatially close $\mathrm{N}$-terminal tail. This result is consistent with a strong localization of the electrostatic interaction due to the compactness of the NP electron plasma.

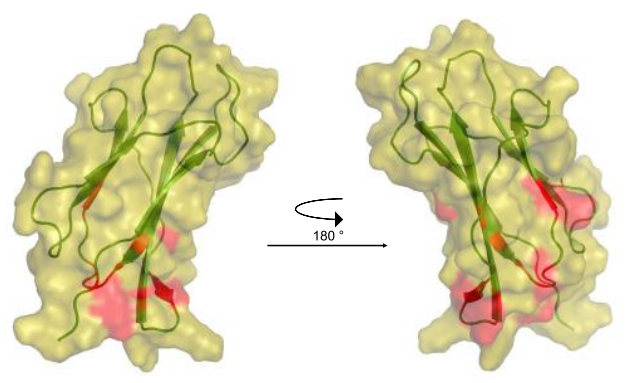

Figure 14. $\beta 2 \mathrm{~m}$ cartoon highlighting in red the locations of the most affected residues by MPA-AuNPs interaction.

Fluorescence study of $\boldsymbol{\beta} \mathbf{2 m}$ in presence of AT-AuNPs From NMR results it can be inferred that while the negatively charged MHA-AuNPs are able to interact and perturb considerably the protein folding stability, the positively charged MUTAB-AuNPs affect the protein structure to a lower extent, at least at the higher investigated protein/NP ratio. To further verify this observation, fluorescence experiments were performed. The buried Trp95 is the main responsible for $\beta 2 \mathrm{~m}$ intrinsic fluorescence, while the exposed Trp60 contribution to the overall fluorescence is limited (20\% approximatively) because of quenching by the solvent (Figure 15a).[34] $\beta 2 \mathrm{~m}$ intrinsic fluorescence was recorded 
upon progressive addition of AuNPs. With MHAAuNPs and MPA-AuNPs, the initial intensity decrease ( 20\%) was followed by intensity increase and shift of the emission peak (Figure 15b and f). By using W60G $\beta 2 \mathrm{~m}$ variant, only the intensity increase and the shift of the emission band could be observed (Figure $15 \mathrm{c}$ and $\mathrm{g}$ ), suggesting that the initial fluorescence attenuation of WT protein reflects the quenching of Trp60 that is exposed on the surface and therefore in direct contact with NPs. When Trp60 is completely quenched, the protein conformation perturbation induced by MHA-AuNPs and MPAAuNPs interaction becomes detectable through fluorescence intensity increase and emission spectrum shift of Trp95. The conformational rearrangement that affects the protein core enclosing Trp95 chromophore was observable within the concentration range 0.08-0.8 nM for MHAAuNPs.

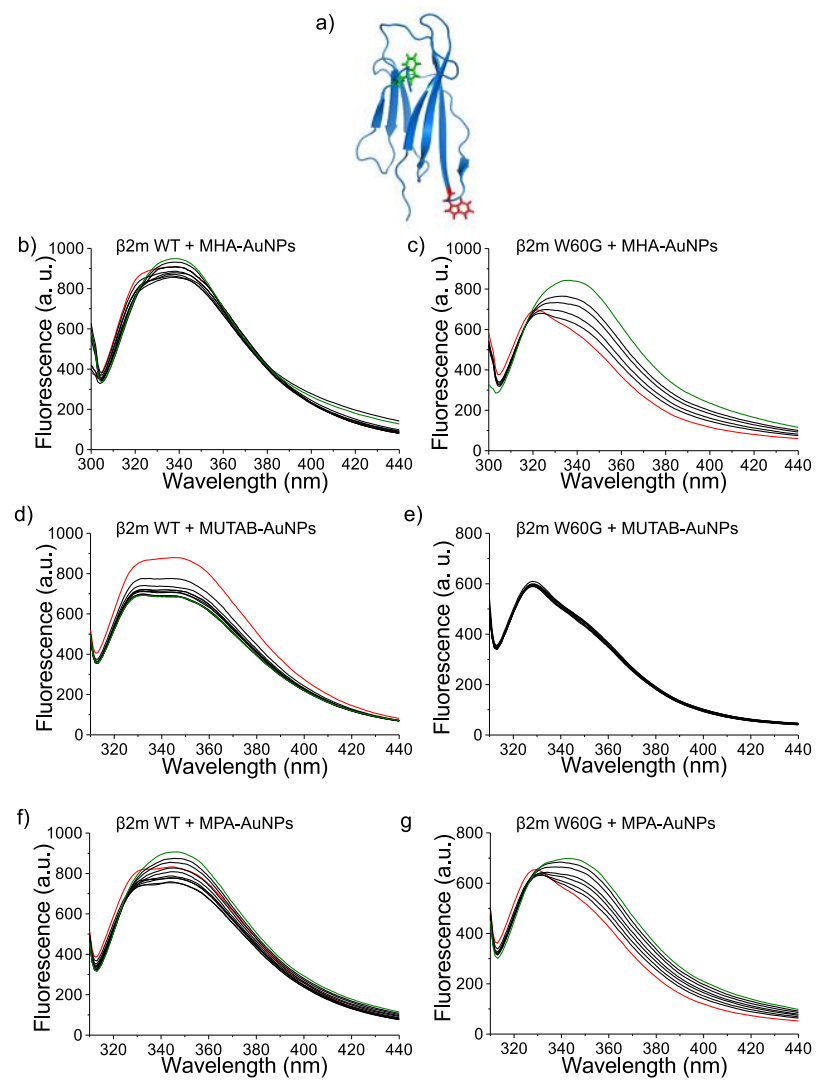

Figure 15. a) Ribbon representation of $\beta 2 \mathrm{~m}$ backbone solution structure[35] highlighting the different exposure of the two tryptophans of the molecule, with the solventexposed W60 (red) and the buried W95 (green). b) and c) Fluorescence quenching of $0.5 \mu \mathrm{M}$ WT and W60G $\beta 2 \mathrm{~m}$, respectively, with MHA-AuNPs (protein/NP from 5000 to 500). d) and e) Fluorescence quenching of $0.5 \mu \mathrm{M}$ WT and W60G $\beta 2 \mathrm{~m}$, respectively, with MUTAB-AuNPs (protein/NP from 5000 to 500). f) and g) Fluorescence quenching of 0.5 $\mu \mathrm{M}$ WT and W60G $\beta 2 \mathrm{~m}$, respectively, with MPA-AuNPs concentrations ranging from 0 to $50 \mathrm{nM}$. The control spectra are coloured in red, while the last titration points in green.

To reach the same effect, MPA-AuNP concentration had to vary from 0.5 to $50 \mathrm{nM}$. Considering that the surface of MPA-AuNP is approximately one fourth of MHA-AuNP surface, we conclude that the perturbation induced by MPA-AuNPs is weaker. This is consistent with previously established evidence of reduced interaction for NP with lower curvature radii.[36] On the other hand, after the initial quenching of Trp60 fluorescence, the titration of $\beta 2 m$ with MUTAB-AuNPs did not show any further emission intensity changes (Figure $15 \mathrm{~d}$ ). This result supports a weak interaction, as inferred from NMR experiments, that is not able to induce any conformational change affecting the core of the protein, at least at the explored protein/NP ratios (from 5000 to 500). The substantial constancy of W60G fluorescence spectra in presence of MUTABAuNPs (Figure 15e) confirms this interpretation. To elucidate the mechanism of Trp60 quenching, the bimolecular quenching constants (kq) were estimated from apparent Stern-Volmer constants (KSV).[37] In addition, $32 \mathrm{~m}$ WT was titrated with MHA alkanethiol alone, as a control. The progressive addition of the MHA produced the same quenching of the Trp60 fluorescence (Figure 16, segmented lines) as observed with all the assessed NP systems.

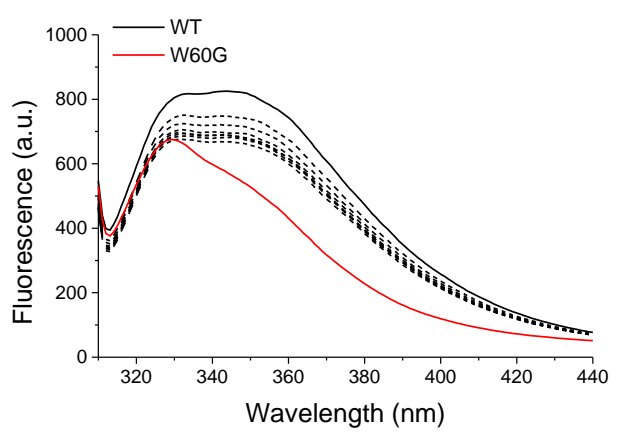

Figure 16. Fluorescence spectra of $0.5 \mu \mathrm{M}$ WT (black solid line) and W60G (red line) $\beta 2 \mathrm{~m}$. The segmented lines correspond to the progressive addition of MHA thiol (from 0 to $100 \mu \mathrm{M}$ ) to WT $\beta 2 \mathrm{~m}$.

By considering a fluorescence lifetime of 1-10 ns for the indole chromophore,[38] the bimolecular calculated quenching constants (Table 1 ) exceed the collisional rate limit, i.e. $2 \times 1010 \mathrm{M}-1 \mathrm{~s}-1$. [38] This 
implies that the mechanism of Trp60 quenching was not purely collisional, apparently even with just the alkanethiol. Surely, the limited number of experimental points affects the accuracy of the obtained $\mathrm{kq}$ values. With an allowance of a couple of orders of magnitude, while the isolated alkanethiol estimate could be reconciled with a collisional mechanism, the values of the bimolecular quenching constant still remain far from diffusional collision rate maximum with AT-AuNPs. In presence of gold nanoparticles, however, quenching mechanisms other than the collisional one are rather plausible, as previously reported.[26]

Table 1 Parameters obtained from fluorescence quenching data fitted by Stern-Volmer equation[37] for MHA-AuNPs, MUTAB-AuNPs, MPA-AuNPs and MHA. To minimize concentration artifacts, only a few initial points of the titration were used for the Stern-Volmer fitting, namely where the fluorescence linearly decreases on titrant concentration increase. The range that is provided for the $\mathrm{kq}$ estimates reflects the uncertainty of the tryptophan fluorescence lifetime (1-10 ns).[38]

\begin{tabular}{llll}
\hline Quencher & $\mathbf{K s v}\left(\mathbf{M}^{-1}\right)$ & $\mathbf{R}^{2}$ & $\boldsymbol{k}_{\mathbf{q}}\left(\mathbf{M}^{-1} \mathbf{s}^{-1}\right)$ \\
\hline $\begin{array}{l}\text { MHA- } \\
\text { AuNPs }\end{array}$ & $5 \times 10^{8}$ & 0.92 & $5 \times 10^{17}-$ \\
& & $5 \times 10^{16}$ \\
\hline $\begin{array}{l}\text { MUTAB- } \\
\text { AuNPs }\end{array}$ & $1 \times 10^{9}$ & 0.95 & $1 \times 10^{18}-$ \\
& & & $1 \times 10^{17}$ \\
\hline MPA- & $1 \times 10^{7}$ & 0.89 & $1 \times 10^{16}-$ \\
AuNPs & & & $1 \times 10^{15}$ \\
& & 0.80 & $9.8 \times 10^{12}-$ \\
\hline MHA & $9.8 \times 10^{3}$ & & $9.8 \times 10^{11}$ \\
& & &
\end{tabular}

\section{AT-AuNPs/ $\mathbf{\beta 2 m}$ interaction mechanism}

NMR, UV-Vis, TEM and fluorescence data suggest that MHA-AuNPs, MPA-AuNPs and MUTAB-AuNPs interact with $\beta 2 \mathrm{~m}$ in different ways leading to diverse scenarios (Figure 17). As for MHA-AuNPs, the interaction with $\beta 2 \mathrm{~m}$ had a destabilizing effect and led to complete precipitation within one month. TEM showed that the precipitate was made of NP agglomerates embedded in a protein matrix. The presence of the protein inside the precipitated aggregates was confirmed also by the loss of the protein NMR signals after one month from sample preparation. On the other hand, a rather extended protein/NP interaction pattern was inferred from the NMR results on freshly prepared samples, based on the scattered positions of the residue locations that were perturbed by the NP presence. Moreover, the onset of new peaks in the random coil region of the NMR spectra revealed that MHA-AuNPs induced $\beta 2 \mathrm{~m}$ unfolding. The capability of MHA-AuNPs to alter considerably $\beta 2 \mathrm{~m}$ structure was proved also by fluorescence experiments which showed an increase in Trp95 fluorescence and a shift of the emission peak. Apparently, another mechanism seems to work in presence of MUTAB-AuNPs. From the substantial invariance of the $\beta 2 \mathrm{~m}$ NMR spectra in presence of MUTAB-AuNPs (at least when the protein was in large excess) and after the proteininduced agglomeration and subsequent precipitation of the NPs, it could be inferred that $\beta 2 \mathrm{~m}$ was mainly released to the bulk solution with only minor conformational changes, if any. This last inference was assessed also by fluorescence titration experiments which did not exhibit any emission increase or shift. An additional proof of the protein exclusion from NP agglomerates came from TEM. Even when the samples were stained with uranyl acetate, no clear evidence of the protein presence in the NP aggregates could be found. Since $\beta 2 \mathrm{~m}$ is slightly negative at physiological $\mathrm{pH}$, the agglomeration of MUTAB-AuNPs is likely to be favoured by the reduction of the NP positive surface charge when the protein is present in solution, as a consequence of electrostatic screening. The role of the electrostatic interactions is further confirmed by the location of the protein interaction patch. Like all macromolecular polyelectrolytes, $\beta 2 \mathrm{~m}$ has an overall dipolar moment that results from a distribution of local partial charges with a relevant negatively charged portion located at the C-terminal region, that in fact proved to be more involved in the interaction with MUTAB-AuNPs at lower protein/NP ratio. This electrostatic-based rationale, however, leads to the puzzling picture of positively charged NPs (MUTAB-AuNPs) that exclude the negatively charged protein, whereas the negatively charged NPs (MHA-AuNPs) include the negatively charged protein. The paradox can be explained by recognizing the relevance of the hydrophobic interactions of the alkyl coatings of the NPs that lead to their agglomeration in presence of $\beta 2 \mathrm{~m}$. The onset of hydrophobic interactions among NPs that compromise their colloidal dispersion is induced by the protein, with the additional contribution from the critical extension of the hydrophobic patches on its surface. Indeed, $\beta 2 \mathrm{~m}$ is an amyloidogenic protein. $[39,40]$ The large hydrophobic aggregation 
drive of the MUTAB chains (11 carbons) is favoured by local screening of the terminal trimethylamonium charges by a negative edge of the protein dipole. This must lead eventually to limited protein incorporation in the precipitated agglomerate as charges are anyway neutralized by bromide anions. The hydrophobic aggregation drive of the MHA chains ( 6 carbons) is smaller than the MUTAB drive and requires screening of the carboxylates by local positive charges of an overall negative protein. The decreased dimension of the alkyl chain with respect to the charged terminal and the relative multiplicity of the screening repertoire of the protein lead to extensive trapping of the latter into the NP agglomerate that eventually precipitates. Therefore, an analogous mechanism based on the proteininduced hydrophobic aggregation of the NP-coating chains and the electrostatic charges of protein and NPs describes the interaction of $\beta 2 \mathrm{~m}$ with MHA- and MUTAB-coated AuNPs. With the small negatively charged MPA-AuNPs a localized region of the protein was found to be affected by the NP presence, i.e. the

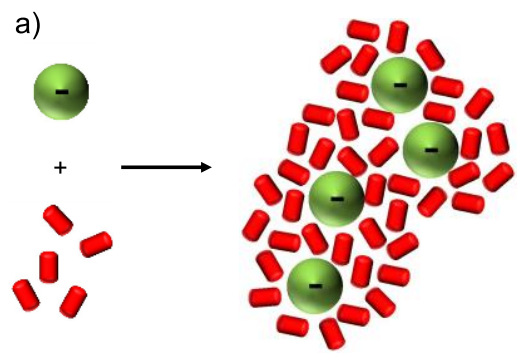

$\beta 2 \mathrm{~m} / \mathrm{MHA}-\mathrm{AuNPs}=600$

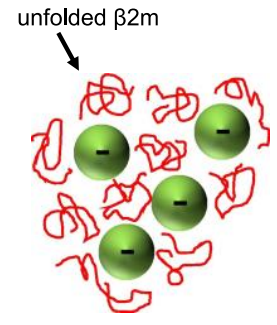

$\beta 2 \mathrm{~m} / \mathrm{MHA}-\mathrm{AuNPs}=300$

$\mathrm{N}$-terminal apical part. As stated before, $\beta 2 \mathrm{~m}$ has an overall molecular dipole with a relevant positive end corresponding to the $\mathrm{N}$-terminal domain through which the protein approaches the negatively charged MPA-AuNP surface. The same $\beta 2 \mathrm{~m}$ interacting region was previously found also with $5 \mathrm{~nm}$ Cit-AuNPs.[41] Compared with the other considered AT-AuNPs, the limited dimension of MPA ( 3 carbons) reduces the relevance of the hydrophobic drive when NPs are challenged with $\beta 2 \mathrm{~m}$, and stresses electrostatics. However, the more restricted involvement of the protein surface and the lower extent of the interaction, as confirmed also by fluorescence, are also due to the small size of MPA-AuNPs. As already reported,[35] when the NP size decreases, the flat surface available for an extended interaction diminishes. These characteristics of $\beta 2 \mathrm{~m} / \mathrm{MPA}$ AuNPs interaction did not drive NP agglomeration, as displayed by TEM images. The MPA-AuNP precipitates, indeed, were not irreversible and could be easily redispersed by sonication.

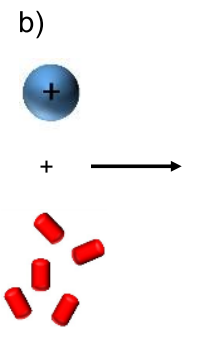

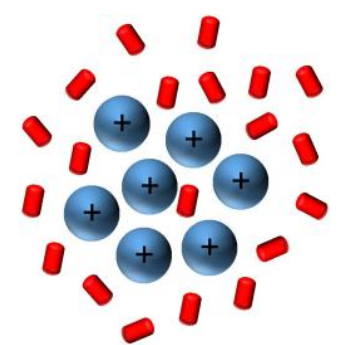

$\beta 2 m / M U T A B-A u N P s=600$

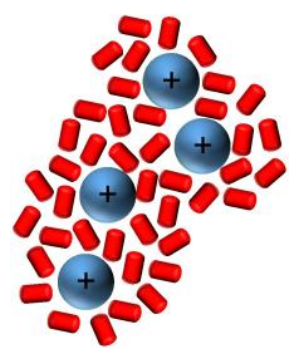

$\beta 2 m /$ MUTAB-AuNPs $=300$
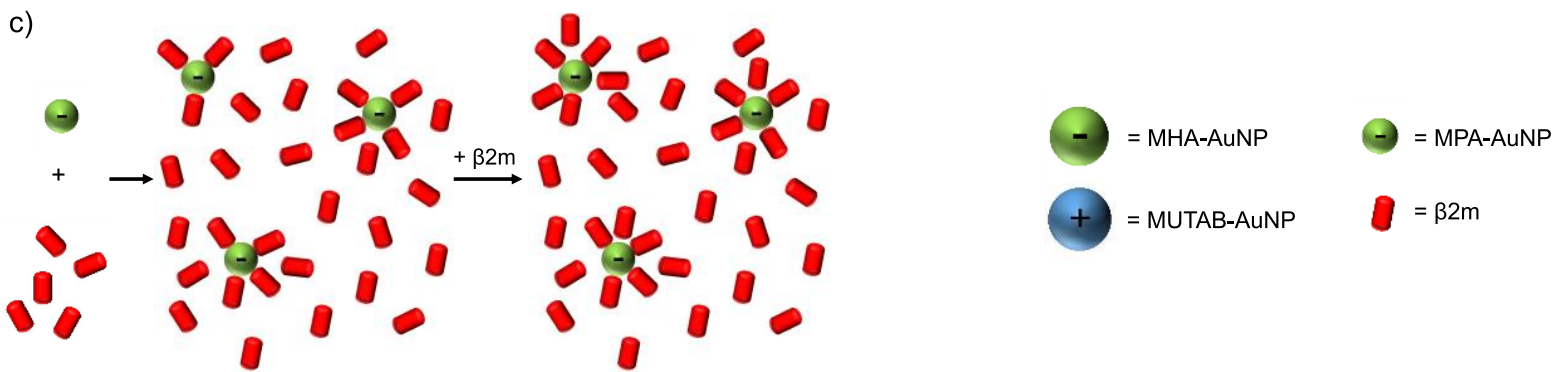

Figure 17. Illustration of the interacting mechanisms of AT-AuNPs with $\beta 2 \mathrm{~m}$ : a) MHA-AuNPs form large precipitating agglomerates with $\beta 2 \mathrm{~m}$ in which the protein undergoes conformational changes leading to unfolding when the NP concentration is raised; $b$ ) at the higher protein/NP ratio here investigated, $\beta 2 \mathrm{~m}$ triggers MUTAB-AuNPs aggregation and precipitation while being released in solution with very minor conformation changes. When, however, the NP concentration is increased, proteins are enforced closer to NPs and undergo conformational perturbation; $c$ ) the interaction between MPA-AuNPs and $\beta 2 \mathrm{~m}$ preferentially involves the N-terminal apical part and keeps the NP stably dispersed. Further addition of protein produces a progressive saturation of the NP binding sites.

\section{Conclusions}

We have examined the effects of different AuNP surface charge and dimensions on the interaction with $\beta 2 m$, a paradigmatic amyloidogenic protein. We found that by changing the physico-chemical properties of AuNPs, different results can be achieved. When $\beta 2 \mathrm{~m}$ is added to otherwise stable AT-AuNPs, hydrophobic aggregation forces develop that basically destabilize the colloidal dispersion. 
While negatively-charged, medium-lengthalkanethiol coatings establish extensive and structure-destabilizing interactions with the protein and slowly precipitate out into protein-NP agglomerates, positively-charged, long-chainalkanethiol coatings incorporate the protein into agglomerates only at high NP concentration, but leave it almost unchanged at lower concentrations, while suddenly precipitating into NP-only aggregates. On the other hand, small, negativelycharged, short-alkanethiol-coated AuNPs engage a dynamic fast-exchange interaction with the protein, while remaining well dispersed. This interaction involves a restricted and specific region of the protein. In essence, the hydrophobic drive, weighted by the alkyl-chain length and the overall NP size, appears further modulated by the charge effects. Our findings highlight the importance of an extensive and individual evaluation of the specific molecular interactions between proteins and AuNPs. Based on our results, the critical role of NP hydrophobic surface, charge and size in determining nanomaterial capability to interact with biomolecules and thus with biological systems reinforces the need for a case-by-case investigation that should be carefully considered when designing nanomaterials-based devices.

\section{Experimental Section}

All reagents were used as received, without further purification. Tetrachloroauric(III) acid trihydrate, trisodium citrate dihydrate, 3-mercaptopropionic acid, 6mercaptohexanoic acid, (11-mercaptoundecyl)-N,N,Ntrimethylammonium bromide and HEPES were purchased from Sigma-Aldrich. $15 \mathrm{~N}$-uniformly-labeled wild-type and W60G $\beta 2 \mathrm{~m}$ came from overexpression in transformed $\mathrm{E}$. coli BL21DE3 strains, according to the procedures previously described.[35] Their concentrations were determined spectroscopically by recording absorbance at $280 \mathrm{~nm}$ using a molar extinction coefficient of 19,940 M-1 $\mathrm{cm}-1$ (WT) and 14,440 M-1 cm-1 (W60G) calculated from the primary sequence using the ExPASY online tool. For any sample preparation, the lyophilized protein was dissolved in $50 \mathrm{mM}$ HEPES buffer at $\mathrm{pH} 7$.

\section{AuNP synthesis and characterization}

All glassware used in nanoparticle synthesis was washed with aqua regia and dried in oven before use.

Cit-AuNPs synthesis. To prepare $7.5 \mathrm{~nm}$ citrate stabilizedgold nanoparticles, an already reported standard cold synthesis using $\mathrm{NaBH} 4$ as gold reducing agent was employed.[26] A solution of sodium citrate dihydrate (1.5 $\mathrm{mM})$ and $\mathrm{HAuCl} 4$ trihydrate $(0.5 \mathrm{mM})$ in milliQ water was reduced under stirring at $0{ }^{\circ} \mathrm{C}$ by $1 \mathrm{~mL}$ of freshly prepared ice-cold $\mathrm{NaBH} 4$ solution $(0.1 \mathrm{M})$. Upon the gold reduction, the solution colour turned from pale yellow to ruby red. UV-Vis spectroscopy and transmission electron microscopy (TEM) were used to check the colloidal nature of the solution and the NP size. The concentration of reduced gold (AuO) was determined by the UV-Vis absorbance of the colloidal solution at $400 \mathrm{~nm}$ [42] and used to estimate the molar concentration of nanoparticles considering the average number of gold atoms per nanoparticle (NAu) expressed by the following equation:[43]

$$
\mathrm{N}_{\mathrm{Au}}=\frac{\pi}{6} \frac{\rho \mathrm{d}^{3}}{\mathrm{M}}=30.89602 \mathrm{~d}^{3}(1)
$$

where $d$ is the nanoparticles diameter $(n m), \rho$ is the density for face-centred cubic gold $(19.3 \mathrm{~g} / \mathrm{cm} 3)$ and $M$ stands for atomic weight of gold $(197 \mathrm{~g} / \mathrm{mol})$.

MHA-AuNPs synthesis. A $10 \mathrm{mM}$ solution of MHA was prepared in ethanol and $1 \mathrm{~mL}$ was added to $5 \mathrm{~mL}$ of CitAuNPs. The solution was stirred for 72 hours at room temperature. The solution became a little darker. MHAAuNPs were concentrated by ultracentrifugation (4000 $\mathrm{rpm}$ for 15 minutes with $10000 \mathrm{MWCO})$. The integrity of AuNPs was assessed by UV-Vis spectroscopy.

MUTAB-AuNPs synthesis. $5 \mathrm{~mL}$ of Cit-AuNPs were extracted with $2 \mathrm{~mL}$ of $\mathrm{CH} 3 \mathrm{Cl}$ in which $1.2 \mu \mathrm{L}$ of oleylamine (OLAM) were dissolved. Once extracted to chloroform the nanoparticles were backwashed three times with water to remove citrate. $330 \mu \mathrm{L}$ of $4 \mathrm{mM}$ MUTAB in ethanol and 500 $\mu \mathrm{L}$ of water were used to bring nanoparticles back to water. To remove OLAM, the aqueous solution was washed with the organic phase three times. MUTABAuNPs were concentrated by ultracentrifugation $(4000$ rpm for 15 minutes with $10000 \mathrm{MWCO}$ ). The integrity of AuNPs was assessed by UV-Vis spectroscopy.

MPA-AuNPs synthesis. $65.3 \mu \mathrm{L}$ of 3-mercaptopropionic acid in deoxygenated water $(5 \mathrm{~mL})$, were added under stirring to a solution of $\mathrm{HAuCl} 43 \mathrm{H} 2 \mathrm{O}$ in deoxygenated methanol $\left(49.2 \mathrm{mg}\right.$ in $5 \mathrm{~mL}$ ) cooled at $0{ }^{\circ} \mathrm{C}$ and purged with nitrogen. Upon the addition of the alkanethiol, the solution became cloudy white and was stirred for two hours. A freshly prepared cooled aqueous solution of $\mathrm{NaBH} 4$ ( $1.25 \mathrm{mmol}, 47.3 \mathrm{mg}$, in $2 \mathrm{~mL}$ of water) was dripped inside the solution. The brown solution obtained was purified by centrifugation $\left(5000 \mathrm{rpm}, 15\right.$ minutes at $25^{\circ} \mathrm{C}$ ) repeating the removal of the supernatant and the dispersion in methanol five times. To determine MPAAuNP molar concentration, the average number of gold atoms per NP (NAu) was calculated from Equation 1 and the number of ligands that are bound to the gold core was estimated from thermogravimetric analysis (TGA). TGA gives the percentage of weight loss during a temperature ramp which is addressed exclusively to the burning of the organic component, following solvent removal. By 
applying Equation 2, it is possible to calculate the monolayer composition:

$$
\mathrm{N}_{\mathrm{L}}=\left(\mathrm{N}_{\mathrm{Au}} \mathrm{M}_{\mathrm{Au}} \mathrm{W} \%\right) /\left((1-\mathrm{W} \%) \mathrm{M}_{\text {thiolate }}\right)(2)
$$

where NL is the number of ligands per NP, W\% is the percentage of weight loss due to organic ligands burning and Mthiolate is the molecular weight of the thiolate molecule. By knowing NAu and NL, the average NP molecular composition can be estimated and the molecular weight calculated. For MPA-AuNPs, the average composition was Au1441(SCH2CH2COO-)661 and the corresponding molecular weight $353,315.33 \mathrm{~g} / \mathrm{mol}$. From these data the molar concentration could be easily calculated. TGA analysis was performed with a SDT Q600 TA instrument under $\mathrm{N} 2$ at a heating rate of $10{ }^{\circ} \mathrm{C} / \mathrm{min}$ going from 0 to $600{ }^{\circ} \mathrm{C}$.

\section{UV-Vis characterization}

For the UV-Vis characterization, a Jasco V-750 was used and the spectra were recorded at $20^{\circ} \mathrm{C}$, from $400 \mathrm{~nm}$ to $800 \mathrm{~nm}$ with a data pitch of $0.2 \mathrm{~nm}$, a scan rate of 200 $\mathrm{nm} / \mathrm{min}$ and a bandwidth of $2 \mathrm{~nm}$. To characterize the interaction of $\beta 2 m$ with MHA-AuNPs and MUTAB-AuNPs (25 nM), absorption spectra were recorded in the presence of increasing amounts of protein (from 0 to 45 $\mu \mathrm{M})$. Only for MHA-AuNPs it was possible to follow the progressive shift of the absorbance maximum and to estimate the binding constant by fitting the data with the Langmuir adsorption isotherm model:[30]

$$
\Delta \lambda=\Delta \lambda_{\max } \frac{\mathrm{K}_{\mathrm{a}}[\beta 2 \mathrm{~m}]}{1+\mathrm{K}_{\mathrm{a}}[\beta 2 \mathrm{~m}]}(3)
$$

where $\Delta \lambda$ is the shift of the SPR band and K_a is the association constant. Each experiment was done in triplicate.

\section{TEM imaging}

To prepare the samples for the TEM imaging, a small amount of the nanoparticle solution was dropped on a TEM grid and left for 5 minutes. Filter paper was used to remove the excess of the solution. When required, the solution was stained with $2 \%$ uranyl acetate solution in water for 2 minutes. A Philips EM 208 microscope was used. The size distribution was calculated by measuring a minimum of 200 particles using ImageJ software.

\section{NMR experiments}

NMR experiments were performed on uniformly $15 \mathrm{~N}$ labeled $\beta 2 \mathrm{~m}$ dissolved in HEPES $50 \mathrm{mM}$ pH 7. D2O (5\%) was added to each sample for lock purposes. The control samples, along with the protein, contained also the free alkanethiols (MHA and MUTAB were added as ethanol solutions). $15 \mathrm{~N}-1 \mathrm{H}$ SOFAST-HMQC experiments[32] were collected on the Bruker Avance spectrometer at the Udine University Biophysics Laboratory, operating at $500 \mathrm{MHz}$ (1H). Experiments were run at $298 \mathrm{~K}$ over spectral widths of $30 \mathrm{ppm}(15 \mathrm{~N}, \mathrm{t} 1)$ and $14 \mathrm{ppm}(1 \mathrm{H}, \mathrm{t} 2)$ with 128 and 1024 points, respectively. A relaxation delay of $0.15 \mathrm{~s}$ was selected and a 3-kHz-bandwidth polychromatic pulse was applied at $8.5 \mathrm{ppm}$ for the selective hydrogen amide excitation. For each t 1 dimension point 800 or 1600 scans were accumulated. The data were processed with Topspin 2.1 and analyzed with Sparky. The $\beta 2 \mathrm{~m}$ assignment was based on the file deposited on the Biological Magnetic Resonance Data Bank (Accession Code: 17165). Chemical shift perturbations were calculated33 as $\Delta \delta(\mathrm{ppm})=$ $[(\Delta \delta H) 2+(\Delta \delta N / 6.5) 2] 1 / 2$ where $\Delta \delta H$ and $\Delta \delta N$ are the chemical shift variations for $1 \mathrm{H}$ and $15 \mathrm{~N}$, respectively. The relative intensities (RI) correspond to the ratio between the signal intensity in presence of NPs and in absence of NPs. The uncertainty related to the relative intensity ratio was calculated applying the propagation of the intensity error estimated from the signal-to-noise ratio.

\section{Fluorescence experiments}

$\beta 2 \mathrm{~m}$ intrinsic fluorescence was recorded in absence of AuNPs and after the progressive addition of small amounts of nanoparticles using a Cary Eclipse Fluorescence Spectrophotometer. For the measurement, fluorescence semi-micro cuvettes were used $(5 \mathrm{~mm} \times 5 \mathrm{~mm})$. The samples were excited at $295 \mathrm{~nm}$ and the emission was recorded from 300 to $450 \mathrm{~nm}$, using $5 \mathrm{~nm}$ slit for both excitation and emission. Each spectrum was the average of 5 consecutive measurements and three individual experiments were repeated for each sample. The initial quenching data were fitted with the linear Stern-Volmer equation:[37]

$$
\frac{\mathrm{F}_{0}}{\mathrm{~F}}=1+\mathrm{K}_{\mathrm{SV}}[\mathrm{Q}]=1+k_{\mathrm{q}} \mathrm{T}_{0}[\mathrm{Q}](4)
$$

where $\mathrm{FO}$ and $\mathrm{F}$ are the fluorescence intensities of the protein in absence and in presence of the quencher $(Q)$, respectively and the Stern-Volmer constant, KSV, is the product of the diffusion-limited bimolecular quenching constant, kq, and the fluorophore fluorescence lifetime, t0.

\section{Acknowledgements}

This work received financial support from Italian Ministry of Education, University and Research (PRIN project No. 2012A7LMS3). We acknowledge New York University Abu Dhabi for access to the Core Technology Platform. We also thank Makek Ads for the assistance.

Keywords: nanoparticles - protein folding • nanotechnology $\bullet$ surface chemistry 
[1] D. A. Giljohann, D. S. Seferos, W. L. Daniel, M. D. Massich, P. C. Patel, C. A. Mirkin, Angew. Chem. Int. Ed. 2010, 49, 3280-3294.

[2] W.-T. Liu, J. Biosci. Bioeng. 2006, 102, 1-7.

[3] M. De, P. S. Ghosh, V. M. Rotello, Adv. Mater. 2008, 20, 4225-4241.

[4] A. M. Alkilany, C. J. Murphy, J. Nanoparticle Res. 2010, 12, 2313-2333.

[5] N. Khlebtsov, L. Dykman, Chem. Soc. Rev. 2011, 40, 1647-1671.

[6] I. Lynch, K. A. Dawson, Nano Today 2008, 3, 4047.

[7] M. Mahmoudi, I. Lynch, M. R. Ejtehadi, M. P. Monopoli, F. B. Bombelli, S. Laurent, Chem. Rev. 2011, 111, 5610-5637.

[8] J. B. Schlenoff, M. Li, H. Ly, J. Am. Chem. Soc. $1995,117,12528-12536$.

[9] K. K. Sandhu, C. M. Mclntosh, J. M. Simard, S. W. Smith, V. M. Rotello, Bioconjug. Chem. 2002, 13, 3-6.

[10] "Conjugation to gold nanoparticles enhances polyethylenimine's transfer of plasmid DNA into mammalian cells," can be found under http://www.pnas.org/content/100/16/9138, n.d.

[11] P. S. Ghosh, C.-K. Kim, G. Han, N. S. Forbes, V. M. Rotello, ACS Nano 2008, 2, 2213-2218.

[12] D. A. Giljohann, D. S. Seferos, A. E. Prigodich, P. C. Patel, C. A. Mirkin, J. Am. Chem. Soc. 2009, 131, 20722073.

[13] J. D. Gibson, B. P. Khanal, E. R. Zubarev, J. Am. Chem. Soc. 2007, 129, 11653-11661.

[14] M.-C. Bowman, T. E. Ballard, C. J. Ackerson, D. L. Feldheim, D. M. Margolis, C. Melander, J. Am. Chem. Soc. 2008, 130, 6896-6897.

[15] G. Han, C.-C. You, B. Kim, R. S. Turingan, N. S. Forbes, C. T. Martin, V. M. Rotello, Angew. Chem. 2006, 118, 3237-3241.

[16] I. H. El-Sayed, X. Huang, M. A. El-Sayed, Nano Lett. 2005, 5, 829-834.

[17] C. Loo, A. Lowery, N. Halas, J. West, R. Drezek, Nano Lett. 2005, 5, 709-711.

[18] Y. Pan, S. Neuss, A. Leifert, M. Fischler, F. Wen, U. Simon, G. Schmid, W. Brandau, W. Jahnen-Dechent, Small 2007, 3, 1941-1949.

[19] D. P. O’Neal, L. R. Hirsch, N. J. Halas, J. D. Payne, J. L. West, Cancer Lett. 2004, 209, 171-176.
[20] C. M. Goodman, C. D. McCusker, T. Yilmaz, V. M. Rotello, Bioconjug. Chem. 2004, 15, 897-900.

[21] M. Chanana, P. Rivera_Gil, M. A. Correa-Duarte, L. M. Liz-Marzán, W. J. Parak, Angew. Chem. Int. Ed. 2013, 52, 4179-4183.

[22] M. Chanana, M. A. Correa-Duarte, L. M. LizMarzán, Small 2011, 7, 2650-2660.

[23] T. A. Faunce, J. White, K. I. Matthaei, Nanomed. 2008, 3, 859-866.

[24] S. Chakraborty, P. Joshi, V. Shanker, Z. A. Ansari, S. P. Singh, P. Chakrabarti, Langmuir 2011, 27, 7722-7731.

[25] "Protein fibrillation and nanoparticle interactions: opportunities and challenges - Nanoscale (RSC Publishing)," can be found under http://pubs.rsc.org/en/content/articlelanding/2013/nr/c 3nr33193h\#!divAbstract, n.d.

[26] C. Cantarutti, S. Raimondi, G. Brancolini, A. Corazza, S. Giorgetti, M. Ballico, S. Zanini, G. Palmisano, P. Bertoncin, L. Marchese, et al., Nanoscale 2017, 9, 39413951.

[27] M. R. Ivanov, H. R. Bednar, A. J. Haes, ACS Nano 2009, 3, 386-394.

[28] J. Hassinen, V. Liljeström, M. A. Kostiainen, R. H. A. Ras, Angew. Chem. Int. Ed. 2015, 54, 7990-7993.

[29] Z. Wang, L. Wu, W. Cai, Chem. - Eur. J. 2010, 16, 1459-1463.

[30] J. A. Yang, B. J. Johnson, S. Wu, W. S. Woods, J. M. George, C. J. Murphy, Langmuir 2013, 29, 4603-4615.

[31] L. Riccardi, L. Gabrielli, X. Sun, F. De Biasi, F. Rastrelli, F. Mancin, M. De Vivo, Chem 2017, 3, 92-109.

[32] P. Schanda, Ē. Kupče, B. Brutscher, J. Biomol. NMR 2005, 33, 199-211.

[33] F. A. A. Mulder, D. Schipper, R. Bott, R. Boelens, J. Mol. Biol. 1999, 292, 111-123.

[34] M. Kihara, E. Chatani, K. Iwata, K. Yamamoto, T. Matsuura, A. Nakagawa, H. Naiki, Y. Goto, J. Biol. Chem. 2006, 281, 31061-31069.

[35] G. Verdone, A. Corazza, P. Viglino, F. Pettirossi, S. Giorgetti, P. Mangione, A. Andreola, M. Stoppini, V. Bellotti, G. Esposito, Protein Sci. Publ. Protein Soc. 2002, 11, 487-499.

[36] S. H. D. P. Lacerda, J. J. Park, C. Meuse, D. Pristinski, M. L. Becker, A. Karim, J. F. Douglas, ACS Nano 2010, 4, 365-379.

[37] J. R. Lakowicz, Principles of Fluorescence Spectroscopy, Springer, New York, 1983. 
[38] M. van de Weert, L. Stella, J. Mol. Struct. 2011, 998, 144-150.

[39] F. Gejyo, T. Yamada, S. Odani, Y. Nakagawa, M. Arakawa, T. Kunitomo, H. Kataoka, M. Suzuki, Y. Hirasawa, T. Shirahama, et al., Biochem. Biophys. Res. Commun. 1985, 129, 701-706.

[40] C. J. D. Foumthuim, A. Corazza, G. Esposito, F. Fogolari, Mol. Biosyst. 2017, 13, 2625-2637.
[41] G. Brancolini, A. Corazza, M. Vuano, F. Fogolari, M. C. Mimmi, V. Bellotti, M. Stoppini, S. Corni, G. Esposito, ACS Nano 2015, 9, 2600-2613.

[42] T. Hendel, M. Wuithschick, F. Kettemann, A. Birnbaum, K. Rademann, J. Polte, Anal. Chem. 2014, 86, 11115-11124.

[43] X. Liu, M. Atwater, J. Wang, Q. Huo, Colloids Surf. B Biointerfaces 2007, 58, 3-7. 


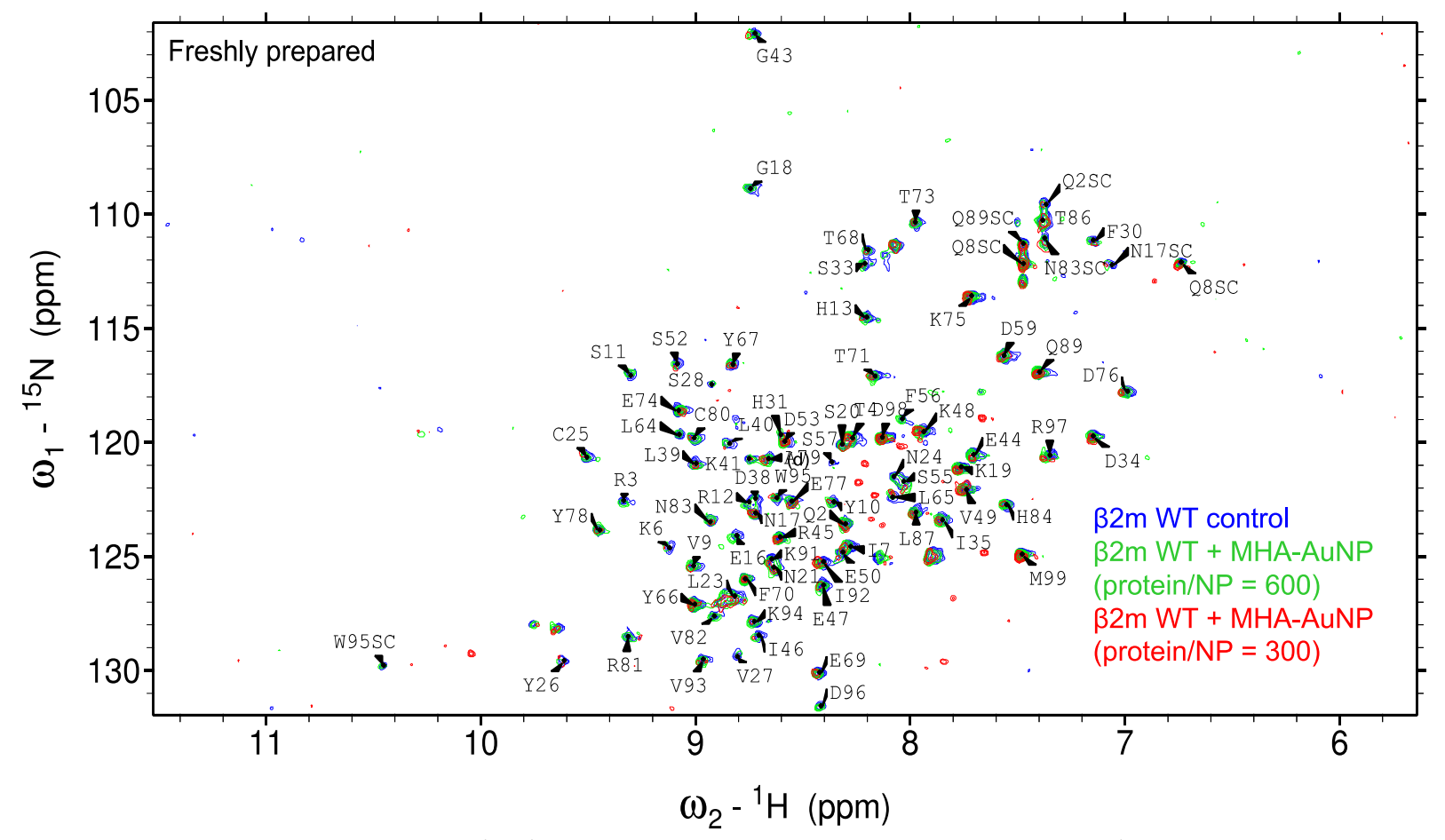

Figure S1. Superimposition of $\beta 2 \mathrm{~m} \mathrm{WT}{ }^{15} \mathrm{~N}-{ }^{1} \mathrm{H}$ SOFAST HMQC spectra recorded at $500 \mathrm{MHz}\left({ }^{1} \mathrm{H}\right.$ frequency) without (blue) and with $\mathrm{MHA}-\mathrm{AuNP}$ (protein/NP = 600 in green and protein/NP = 300 in red). The corresponding backbone amide assignments are reported by single letter code and the side-chain amides are indicated by SC.

(a)

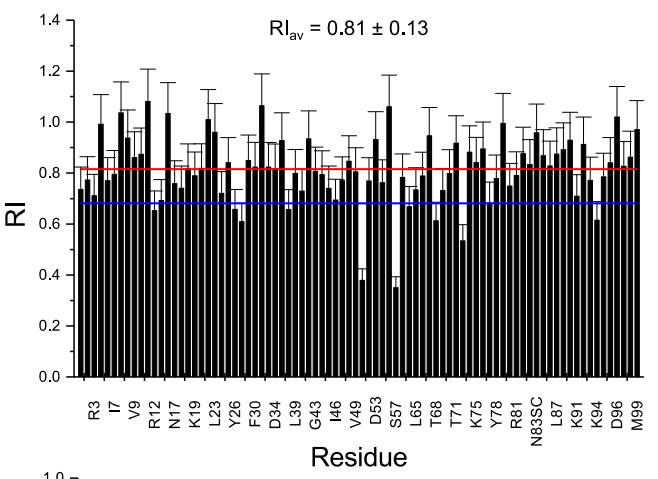

(c)

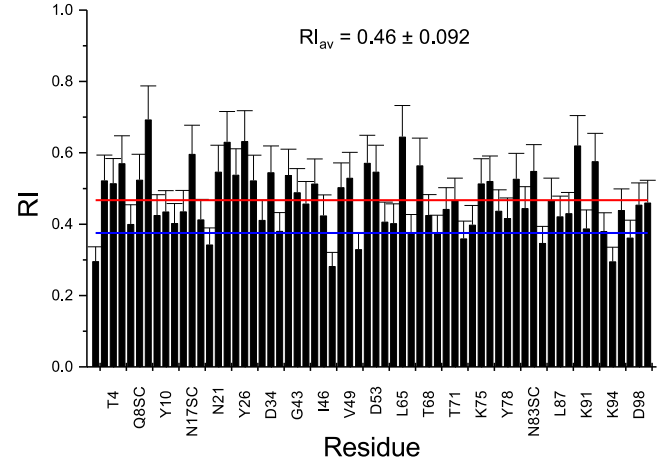

(b)

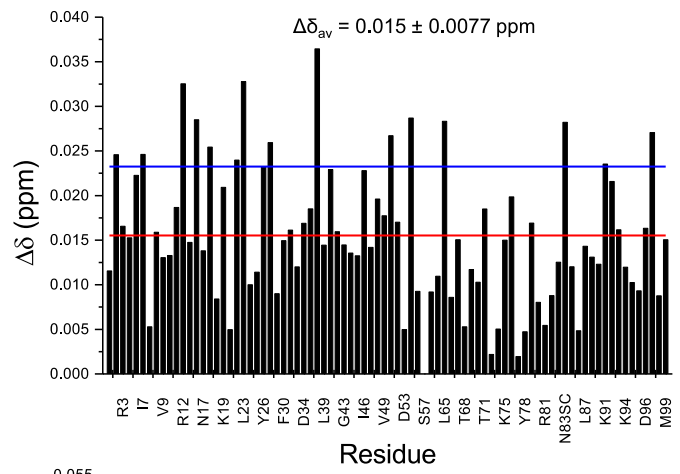

(d)

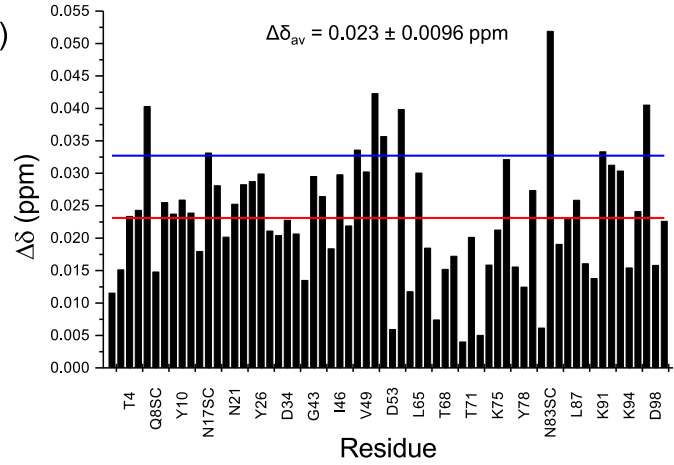

Figure S2. a) and b) Bar plots of $\beta 2 \mathrm{~m}$ amide cross-peak attenuations (RI) and combined chemical shift perturbations $(\Delta \bar{\delta})$, respectively, against the protein sequence, at protein/ MHA-AuNP $=600$. c) and d) Bar plots of $\beta 2 \mathrm{~m}$ amide cross-peak attenuations $(\mathrm{RI})$ and combined chemical shift perturbations $(\Delta \delta)$, respectively, against the protein sequence, at protein/MHAAuNP $=300$. The horizontal lines indicate, respectively, the average values (red) and the displacement of one standard deviation (blue) above or below the average. To avoid graphic crowding, the abscissa labels of the panels were reported only every other three residues. Besides the observed backbone amides, also the following side-chain (SC) NH resonances were detected and included in the abscissa label list, according to the primary sequence order: Q2, Q8 (two separate signals), N17, N83, Q89, W95. The missing labels do not include the following unobserved or non-existing backbone NH connectivities: I1, P5, 
Q8, P14, A15, F22, G29, P32, E36, V37, N42, H51, L54, K58, W60, S61, F62, Y63, P72, V85, S88, P90. In addition to the listed residues, also R3, S11, R12, N24, V27, S28, H31, D38, L40, K41, F56, S57, L64, C80, R81, V82 and D96 were unobservable in the SOFAST HMQC maps from the solution with a higher NP concentration. It is worth highlighting that SOFAST experiments are very convenient to screen quickly the appearance of the two-dimensional NMR spectra, but they have a lower signal-tonoise ratio and non-uniform excitation artefacts compared to HSQC spectra acquired with same number of scans. To compromise between the need of minimising the measurement time and the necessity of quantification, acquisitions were typically limited to $\sim 6-12$ hours. The appreciable uncertainty on intensity measurements limited the confidence threshold for some of the observed changes. For instance, with a typical $\Delta$ (intensity) around $8 \%$, all the values above unity in panel (a) in the spectrum recorded in presence of MHA-AuNPs should be considered with caution.

Table S1. Synopsis of WT $\beta 2 \mathrm{~m}$ amides that proved most affected by the presence of MHA-AuNP, i.e. displaced more than one standard deviation from the average $\Delta \delta$ and RI values. The amides are grouped according to the secondary structure element location.

\begin{tabular}{|c|c|c|c|c|}
\hline Structure region & $\begin{array}{l}\Delta \delta \text { outliers } \\
\beta 2 \mathrm{~m} / \mathrm{NP}=600\end{array}$ & $\begin{array}{l}\text { RI outliers } \\
\beta 2 \mathrm{~m} / \mathrm{NP}=600\end{array}$ & $\begin{array}{l}\Delta \delta \text { outliers } \\
\beta 2 \mathrm{~m} / \mathrm{NP}=300\end{array}$ & $\begin{array}{l}\text { RI outliers } \\
\beta 2 \mathrm{~m} / \mathrm{NP}=300\end{array}$ \\
\hline N-term, A strand & 17 & & 17 & \\
\hline AB loop & R12, E16, N17SC & R12 & N17SC & $\mathrm{S} 20$ \\
\hline B strand & N21SC, L23, V27 & Y26, V27 & L23 & Y26 \\
\hline \multicolumn{5}{|l|}{ BC loop } \\
\hline CC', C'D loops & D38 & D38 & K48 & $\mathrm{E} 47$ \\
\hline D strand & E50 & E50 & E50, S52 & E50 \\
\hline DE loop & S55 & S57 & S55 & \\
\hline E strand & L65 & L64, T68 & L65 & T68 \\
\hline EF loop & & $\mathrm{T} 73$ & & T73, E69 \\
\hline F strand & $\mathrm{H} 84$ & & N83SC, H84 & $\mathrm{H} 84$ \\
\hline \multicolumn{5}{|l|}{ FG loop } \\
\hline G strand, C-term & K91, R97 & K94 & K91 & K94 \\
\hline
\end{tabular}




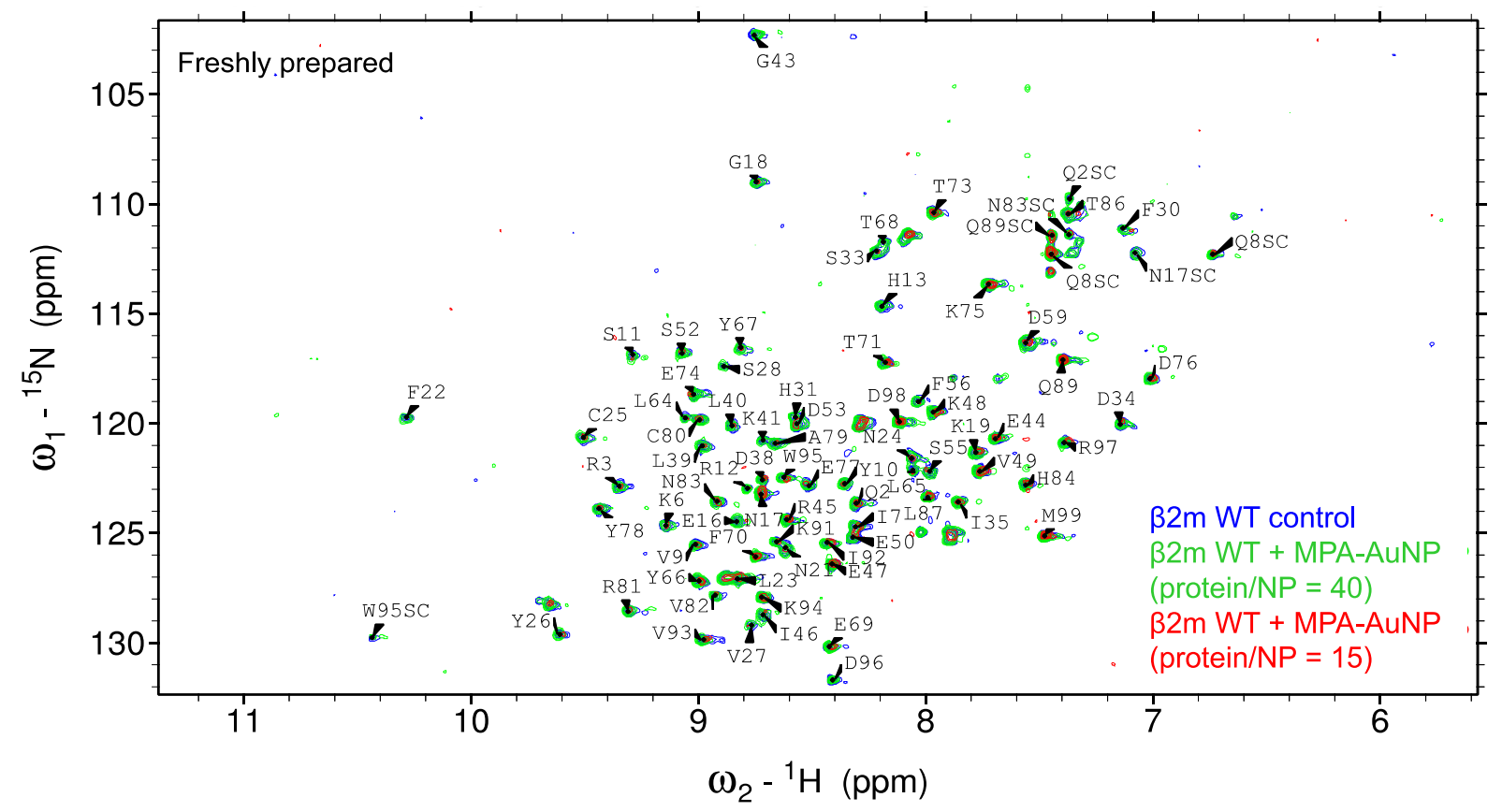

Figure S3. Superimposition of $\beta 2 \mathrm{~m} \mathrm{WT}{ }^{15} \mathrm{~N}-{ }^{1} \mathrm{H}$ SOFAST HMQC spectra recorded at $500 \mathrm{MHz}\left({ }^{1} \mathrm{H}\right.$ frequency) without (blue) and with MUTAB-AuNP (protein/NP = 600 in green and protein/NP = 300 in red). The corresponding backbone amide assignments are reported by single letter code and the side-chain amides are indicated by SC.

(a)

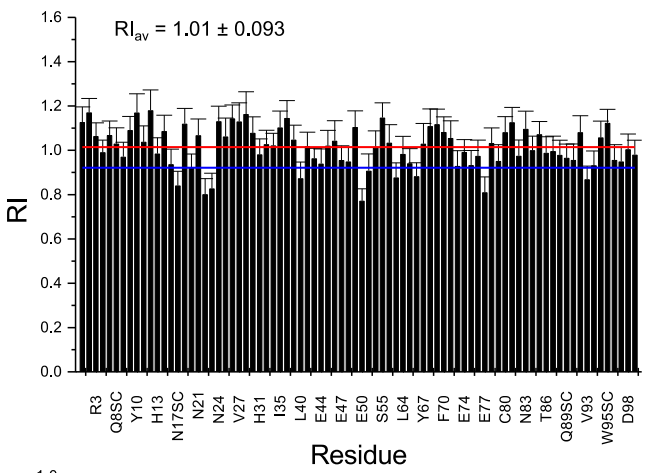

(c)

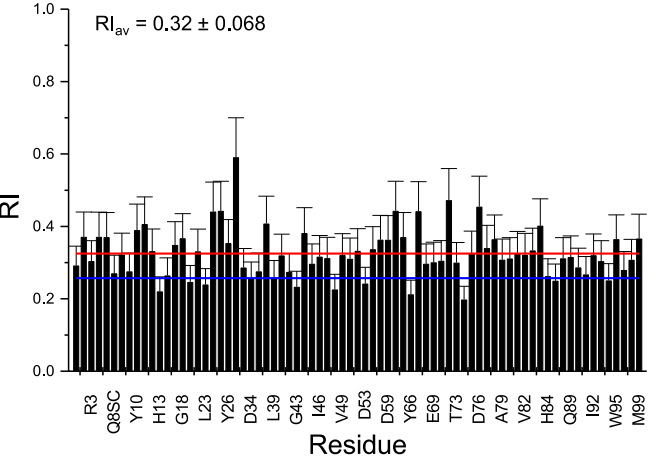

(b)

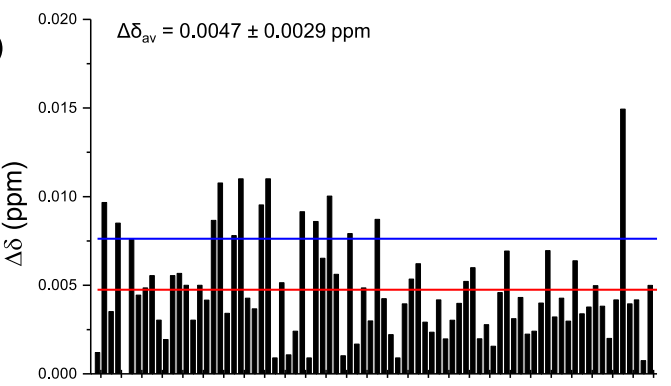

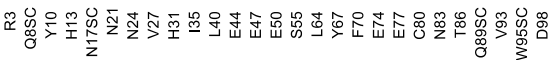

(d)

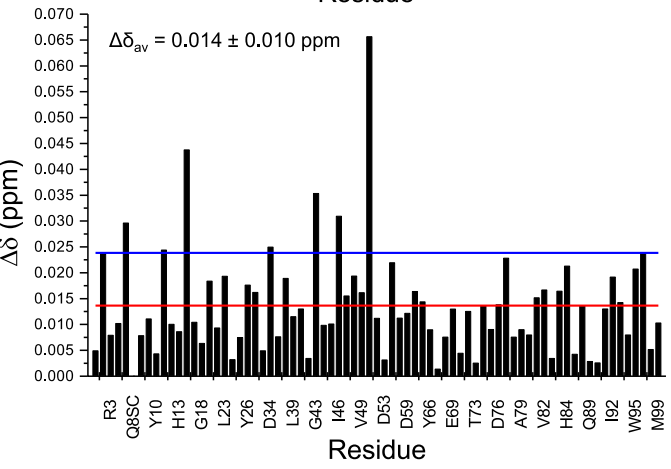

Figure S4. a) and b) $\beta 2 \mathrm{~m}$ amide cross-peak attenuations (RI) and combined chemical shift perturbations $(\Delta \delta)$, respectively, against the protein sequence, at protein/ /MUTAB-AuNP $=600$. c) and d) $\beta 2 \mathrm{~m}$ amide cross-peak attenuations (RI) and combined chemical shift perturbations $(\Delta \delta)$, respectively, against the protein sequence, at protein/ /MUTAB-AuNP $=300$. The horizontal lines indicate, respectively, the average values (red) and the displacement of one standard deviation (blue) above or below the average. To avoid graphic crowding, the abscissa labels of the panels were reported only every other three residues. Besides the observed backbone amides, also the following side-chain (SC) NH resonances were detected and included in the abscissa label list, according to the primary sequence order: Q2, Q8 (two separate signals), N17, N83, Q89, W95. The missing labels do not include the following unobserved or non-existing backbone NH connectivities: I1, T4, P5, Q8, P14, A15, S20, G29, P32, E36, V37, N42, H51, L54, S57, K58, W60, S61, F62, Y63, P72, V85, S88, P90. In addition to the listed residues, also F22, $\mathrm{S} 28, \mathrm{~F} 30, \mathrm{H} 31$ and D96 were unobservable in the spectrum of the solution with a higher NP concentration. 
Table S2. Synopsis of WT $\beta 2 \mathrm{~m}$ amides that proved most affected by the presence of MUTAB-AuNP, i.e. displaced more than one standard deviation from the average $\Delta \delta$ and RI values. The amides are grouped according to the secondary structure element location.

\begin{tabular}{|c|c|c|c|c|}
\hline Structure region & $\begin{array}{l}\Delta \delta \text { outliers } \\
\beta 2 \mathrm{~m} / \mathrm{NP}=600\end{array}$ & $\begin{array}{l}\text { RI outliers } \\
\beta 2 \mathrm{~m} / \mathrm{NP}=600\end{array}$ & $\begin{array}{l}\Delta \delta \text { outliers } \\
\beta 2 \mathrm{~m} / \mathrm{NP}=300\end{array}$ & $\begin{array}{l}\text { RI outliers } \\
\beta 2 \mathrm{~m} / \mathrm{NP}=300\end{array}$ \\
\hline N-term, A strand & & & 17, S11 & \\
\hline AB loop & & N17SC, K19 & E16 & $\mathrm{H} 13, \mathrm{~K} 19$ \\
\hline B strand & $\mathrm{F} 22, \mathrm{C} 25$ & F22, L23 & & L23 \\
\hline BC loop & F30 & & D34 & D34 \\
\hline CC', C'D loops & & L40 & G43, 146 & G43 \\
\hline D strand & & E50 & E50 & K48 \\
\hline DE loop & & S52, D59 & & D53 \\
\hline E strand & & Y66 & & \\
\hline EF loop & & E77 & & E74 \\
\hline \multicolumn{5}{|l|}{ F strand } \\
\hline FG loop & & & & T86 \\
\hline G strand, C-term & W95SC & V93 & R97 & K94 \\
\hline
\end{tabular}

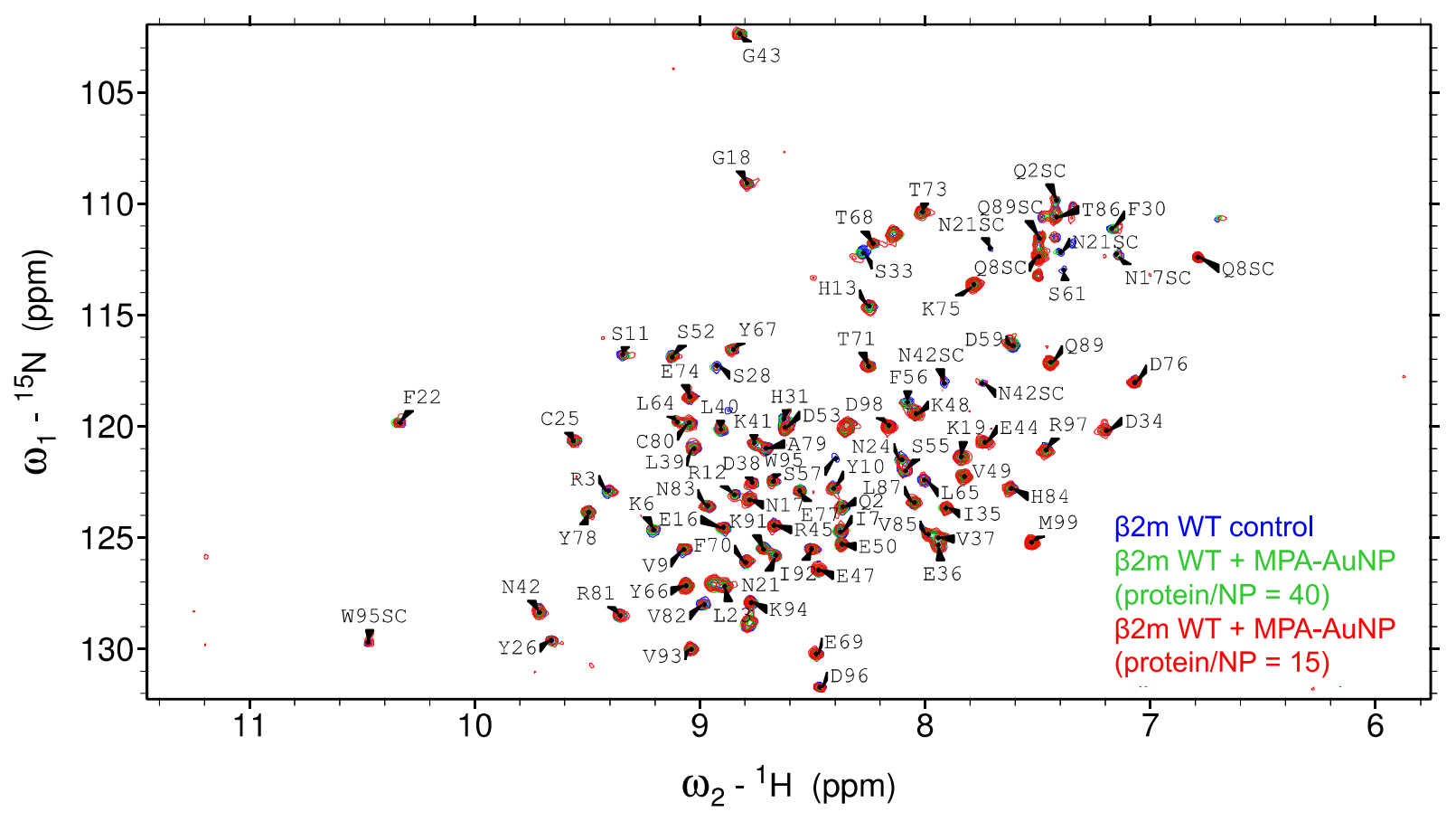

Figure S5. Superimposition of $\beta 2 \mathrm{~m}^{1} \mathrm{H}^{15} \mathrm{~N}$ SOFAST HMQC spectra recorded at $500 \mathrm{MHz}\left({ }^{1} \mathrm{H}\right.$ frequency) in absence of MPAAuNPs (blue) and in presence of MPA-AuNPs with protein/NP ratio of 40 (green) and of 15 (red). The corresponding backbone amide assignments are reported by single letter code and the side-chain amides are indicated with SC. 
(a)

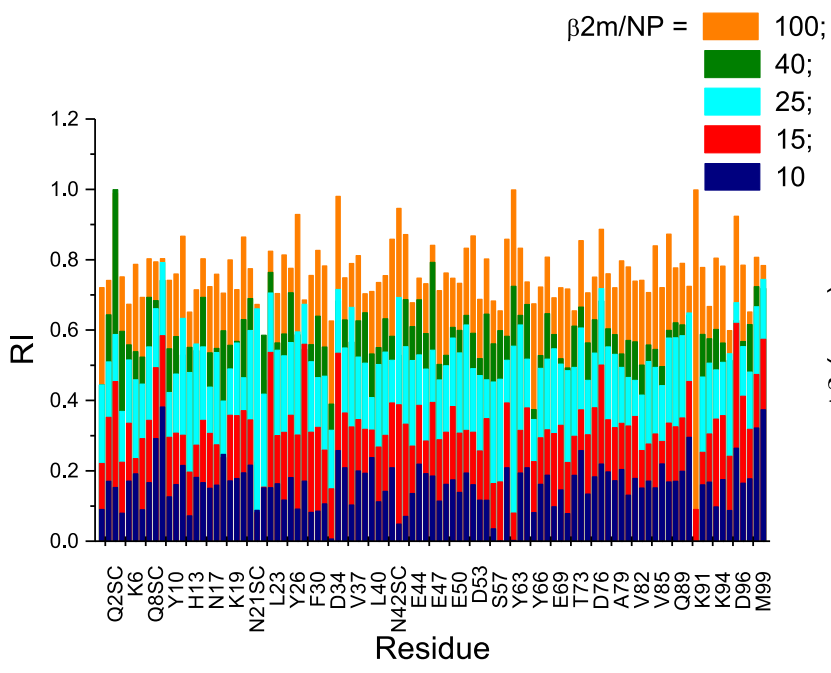

(b)

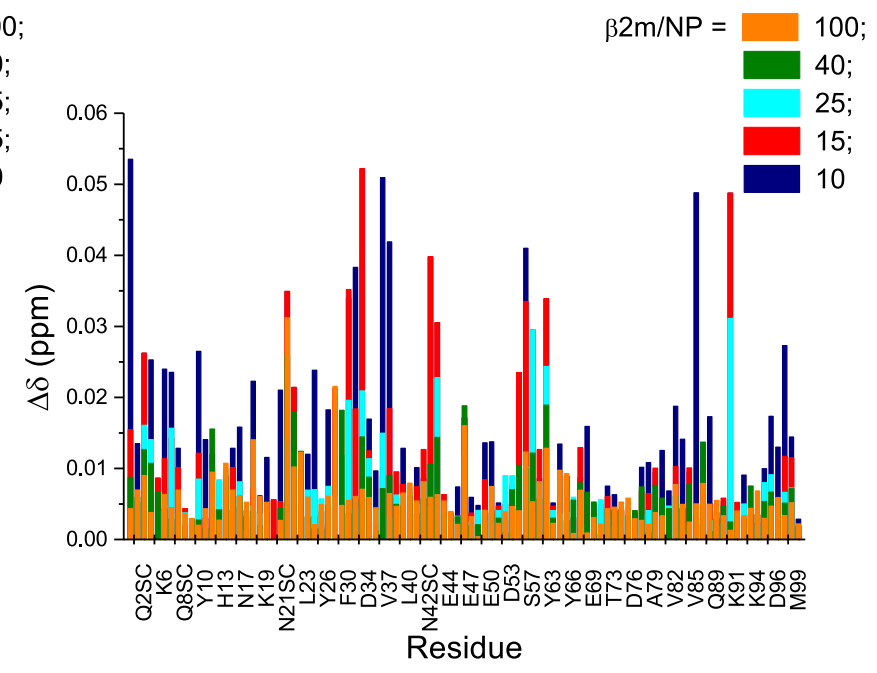

Figure S6. a) and b) $\beta 2 m$ amide cross-peak attenuations (RI) and combined chemical shift perturbations $(\Delta \delta)$, respectively, against the protein sequence, at different protein/MPA-AuNP ratios. Refer to color legend for the protein/MPA-AuNP ratios colour attributions. To avoid graphic crowding, the abscissa labels of the panels were reported only every other three residues. Besides the observed backbone amides, also the following side-chain (SC) NH resonances were detected and included in the abscissa label list, according to the primary sequence order: Q2, Q8, N17, N83, Q89, W95. The missing labels do not include the following unobserved or non-existing backbone NH connectivities: I1, P5, P14, G29, P32, L54, K58, D59, W60, F62, P72, S88, and P90. In addition to the listed residues, also R3, S11, R12, N24, V27, S28, H31, D38, L40, K41, F56, S57, L64, C80, $\mathrm{R} 81, \mathrm{~V} 82$ and D96 were unobservable in the spectra of the solution with increasing NP concentrations.

Table S3. Synopsis of WT $\beta 2 \mathrm{~m}$ amides that proved most affected by the presence of MPA-AuNP, i.e. displaced more than one standard deviation from the average $\Delta \delta$ and RI values. The amides are grouped according to the secondary structure element location.

\begin{tabular}{|l|l|l|}
\hline Structure region & $\Delta \delta$ outliers & RI outliers \\
\hline N-term, A strand & R3 & R3 \\
\hline AB loop & & \\
\hline B strand & & S28 \\
\hline BC loop & F30, H31, S33 & F30, H31, S33 \\
\hline CC', C'D loops & E36, V37 & \\
\hline D strand & & \\
\hline DE loop & S55, F56, S57, S61 & F56, S57, S61 \\
\hline E strand & & L65 \\
\hline EF loop & & \\
\hline F strand & & \\
\hline FG loop & & \\
\hline G strand, C-term & & \\
\hline
\end{tabular}

